\title{
Assessing uncertainty of hydrological and ecological parameters originating from the application of an ensemble of ten global-regional climate model projections in a coastal ecosystem of the lagoon of Venice, Italy
}

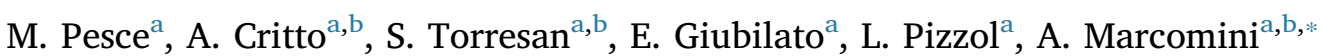 \\ ${ }^{\text {a }}$ University $\mathrm{Ca}$, Foscari of Venice, Italy \\ ${ }^{\mathrm{b}}$ Centro Euro-Mediterraneo sui Cambiamenti Climatici, Italy
}

A R T I C L E I N F O

\section{Keywords:}

Climate change

Uncertainty analysis

Phytoplankton

Hydrology

SWAT

AQUATOX

\begin{abstract}
A B S T R A C T
With increasing evidences of climate change affecting coastal waters, there is a strong need to understand future climate conditions and assess the potential responses of delicate coastal ecosystems. Results of climate change studies based on only one GCM-RCM combination should be interpreted with caution as results are highly dependent on the assumptions of the selected combination. In this study we examined the uncertainty in the hydrological and ecological parameters of the Zero river basin (ZRB) - Palude di Cona (PDC) coastal aquatic ecosystem generated by the adoption of an ensemble of climate projections from ten different combinations of General Circulation Model (GCM) - Regional Climate Model (RCM) under two emission scenarios (RCP4.5 and RCP8.5) implemented in the hydrological model (SWAT) and the ecological model (AQUATOX). The baseline period of 1983-2012 was used to identify climate change variations in two future periods: mid-century (2041-2070) and late-century (2071-2100) periods. SWAT outputs from the ensemble indicate a summer reduction in inorganic nitrogen loadings of $1-22 \%$ and a winter increase of $1-19 \%$. Inorganic phosphorus loadings indicate a yearly increase of 32-61\%. AQUATOX outputs from the ensemble show major changes in the summer period, with an increase in Chl-a concentration of 9-56\%, a decrease in diatoms of 74-98\% and an increase in cyanobacteria of $421-3590 \%$. Obtained results confirm that the use of multiple GCM-RCM projections can provide a more robust assessment of climate change impacts on the hydrology and ecology of coastal waters, but at the same time highlight the large uncertainty of climate change-related impact studies, which can affect the decision-making processes regarding the management and preservation of sensitive aquatic ecosystems such as those in coastal areas.
\end{abstract}

\section{Introduction}

The scientific community agrees unequivocally that anthropogenic emissions of greenhouse gases (GHGs) are warming the Earth's climate (Cook et al., 2016). Continued emissions of GHGs are expected to cause a rise of the global mean temperatures by $0.3-4.8^{\circ} \mathrm{C}$ by the end of the 21 st century relative to the period 1986-2005, inducing long-lasting changes in all components of the climate system (IPCC, 2013).

Changes in the global climate system are expected to have major consequences for aquatic ecosystems, including those of coastal areas (Altieri and Gedan, 2015; Glibert et al., 2014; Rabalais et al., 2009; Snickars et al., 2015). Being situated at the interface between land and sea, coastal ecosystems are subjected to the combined changes in the atmosphere, oceans, and over the land surface (Raimonet and Cloern, 2016). Such changes in turn impact the benefits that coastal ecosystems provide to society such as coastal protection, water purification, nutrient cycling and recreation activities (Barbier et al., 2011).

Several studies point out the increasing evidences of the impacts of climate change on coastal phytoplankton, which plays a central role in biogeochemical cycles and is responsible for a large share of primary production of coastal areas (Cloern and Jassby, 2008; Harding et al., 2015; Holt et al., 2016; Huertas et al. 2011; Pesce et al., 2018). While oceanic phytoplankton has a predictable yearly cycle, seasonal changes of coastal phytoplankton is highly variable and complex. Therefore, there is an urgent need to comprehensively explore the future climatic conditions and try to anticipate the possible responses to climate change of phytoplankton in coastal waters.

Climate projections are functional tools that can drive hydrological and ecological models to attempt the assessment of climate change impacts on aquatic ecosystems. Climate projections are plausible

\footnotetext{
* Corresponding author.

E-mail address: marcom@unive.it (A. Marcomini).
} 


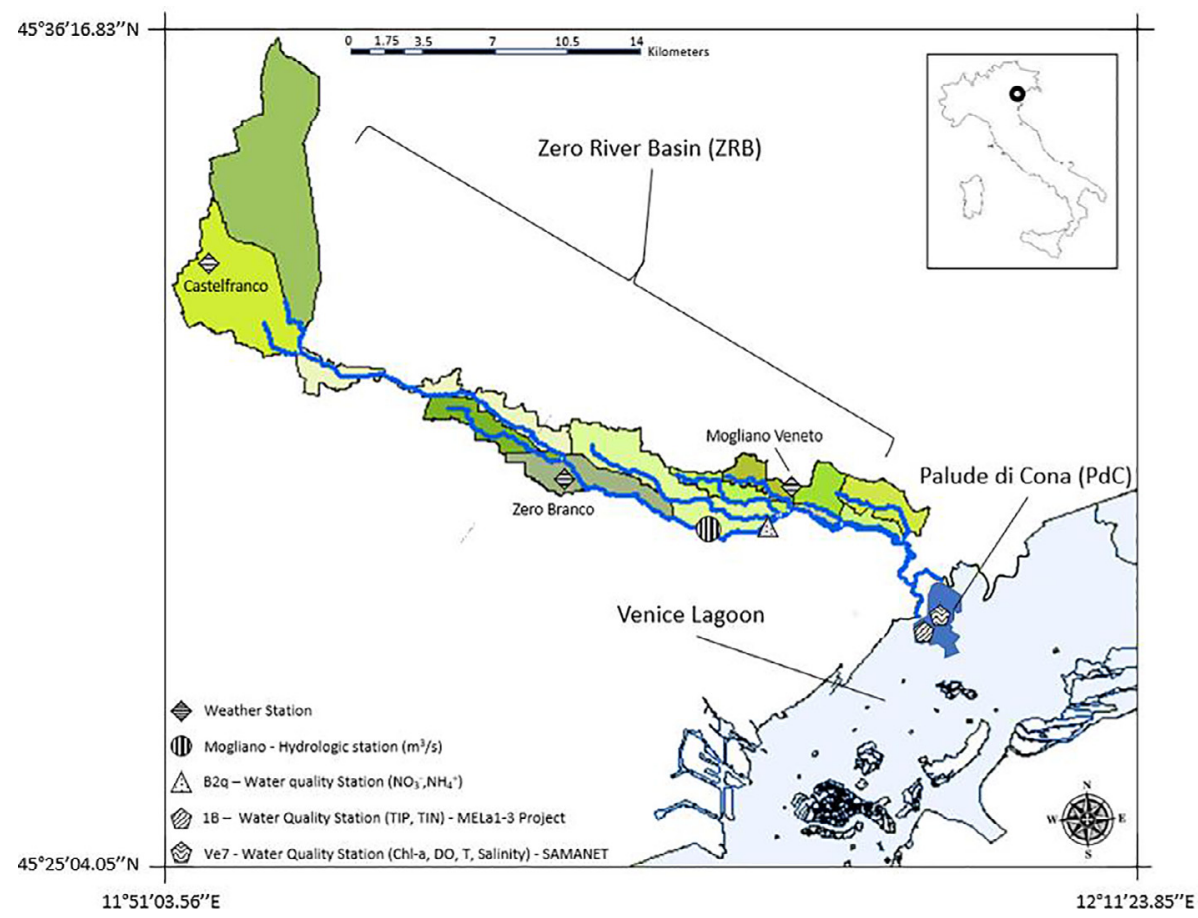

Fig. 1. Map representing the Zero River Basin (ZRB) and its sub-basins, Palude di Cona (PDC) and the monitoring stations used in the study.

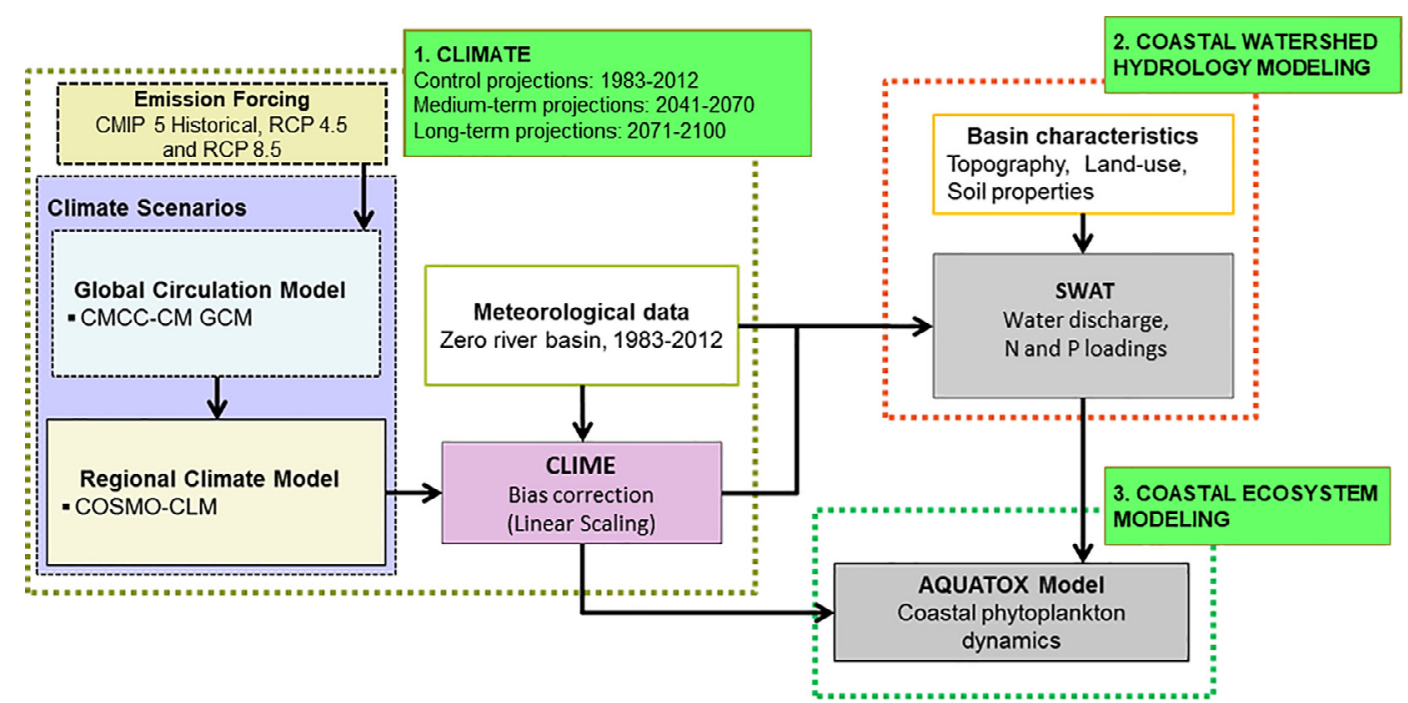

Fig. 2. Workflow of the integrated modelling approach applied in the study.

representations of future climate conditions and are the result of the application of climate models based on GHGs emission and concentration scenarios (Moss et al., 2010). Specifically, a General Circulation Model (GCM) is the primary tool in the generation of climate projections. GCMs simulate the principal dynamics of the physical components of the climate system (atmosphere, ocean, land and ice) with a spatial horizontal resolution between 250 and $600 \mathrm{~km}$ (Mechoso and Arakawa, 2015). However, there is an evident discrepancy between this resolution and the scale of local hydrological and ecological processes. As a result, environmental models driven directly by GCMs often provide outputs with poor performance (Fowler et al., 2007). Various downscaling methods have been developed to bridge this gap, from simple regression models that change the values of meteorological time series (Ficklin et al., 2009; Somura et al., 2009) to more complex dynamical methods (Caldwell et al., 2009; Giorgi and Gutowski, 2015; Xue et al., 2014). A common solution to providing local projections of the climate is to dynamically downscale GCMs projections by using its outputs to drive a Regional Climate Model (RCM). RCMs usually have a resolution that goes from 50 to $8 \mathrm{~km}$ (Jacob et al., 2014) and add further detail to GCMs by increasing the spatial resolution of a limited area of interest by capturing the fundamental climatic and morphologic features of that area (Rummukainen, 2010).

The simulated projections of the future climate are subject to uncertainties that can be handled by using an ensemble of different climate models. Hawkins and Sutton $(2009,2011)$ identifies three major categories of uncertainty: (i) scenario uncertainty, (ii) internal climate variability and (iii) model uncertainty. Scenario uncertainty refers to the uncertainties arising due to our limited understanding of future emissions, GHG concentrations or forcing trajectories. Internal climate variability describes the variability of the major climate system components (atmosphere, hydrosphere, cryosphere, land surface, and biosphere) and their coupled interactions. Finally, model uncertainty is 
Table 1

Calibration and validation results for the SWAT and AQUATOX models applied to the ZRB and PDC case study. The coefficient of determination $\left(\mathrm{R}^{2}\right)$, the NashSutcliffe Efficiency Index, NSE (Nash and Sutcliffe, 1970), and the overlap between data and model distribution based on relative bias (rB) and variance (F) were performed depending on the availability of data and model. For a comprehensive description please refer to Pesce et al. (2018).

\begin{tabular}{|c|c|c|c|c|}
\hline \multirow[t]{3}{*}{ Parameter } & \multicolumn{4}{|l|}{ SWAT } \\
\hline & \multicolumn{2}{|c|}{ Calibration (2007-2009) } & \multicolumn{2}{|c|}{ Validation (2010-2012) } \\
\hline & $\mathrm{R}^{2}$ & NSE & $\mathrm{R}^{2}$ & NSE \\
\hline $\mathrm{Q}\left(\mathrm{m}^{3} / \mathrm{s}\right)$ & 0.63 & 0.58 & 0.61 & 0.20 \\
\hline $\mathrm{N}-\mathrm{NO}_{3}{ }^{-}$(t/mo.) & 0.80 & 0.60 & 0.65 & 0.25 \\
\hline \multirow[t]{3}{*}{$\mathrm{N}-\mathrm{NH}_{4}{ }^{+}$(t/mo.) } & 0.59 & 0.51 & 0.25 & -0.10 \\
\hline & \multicolumn{2}{|c|}{ Calibration (2007-2009) } & \multicolumn{2}{|c|}{ Validation (2010-2012) } \\
\hline & $\begin{array}{l}\text { Relative bias } \\
(\mathrm{rB})\end{array}$ & $\begin{array}{l}\text { Variance ratio } \\
\text { (F) }\end{array}$ & $\begin{array}{l}\text { Relative bias } \\
(\mathrm{rB})\end{array}$ & $\begin{array}{l}\text { Variance ratio } \\
\text { (F) }\end{array}$ \\
\hline $\mathrm{P}-\mathrm{PO}_{4}{ }^{3-}(\mathrm{t} / \mathrm{mo})$. & -0.56 & 0.74 & 0.03 & 1.11 \\
\hline \multirow[t]{2}{*}{ Parameter } & & \multicolumn{3}{|c|}{$\begin{array}{l}\text { AQUATOX } \\
\text { Performance period (2007-2011) }\end{array}$} \\
\hline & & \multicolumn{2}{|l|}{ Relative bias (rB) } & Variance ratio $(\mathrm{F})$ \\
\hline Sol. Rad. (Lyd/d) & & -0.03 & & 0.91 \\
\hline Wind speed $(\mathrm{m} / \mathrm{s})$ & & -0.38 & & 2.14 \\
\hline DO (mg/l) & & 0.16 & & 0.17 \\
\hline DIN (mg/l) & & 0.14 & & 0.18 \\
\hline DIP (mg/l) & & 0.76 & & 0.44 \\
\hline DIN:DIP & & -0.66 & & 0.34 \\
\hline Chl-a ( $\mu g / 1)$ & & -0.01 & & 1.32 \\
\hline
\end{tabular}

Q: waterflow; DO: dissolved oxygen; DIN: dissolved inorganic nitrogen; DIP: dissolved inorganic phosphorus.

Table 2

Scenarios adopted in the study. Mid-century (2041-2070) and late-century (2071-2100) simulated periods were compared with the baseline simulated period (1983-2012).

\begin{tabular}{lll}
\hline Emission scenario & Time frames & \multicolumn{1}{l}{ Years } \\
\hline Historical & Baseline & $1983-2005$ \\
RCP4.5 & & $2006-2012$ \\
RCP8.5 & & $2006-2012$ \\
RCP4.5 & Mid-century & $2041-2070$ \\
& Late-century & $2071-2100$ \\
RCP8.5 & Mid-century & $2041-2070$ \\
& Late-century & $2071-2100$ \\
\hline
\end{tabular}

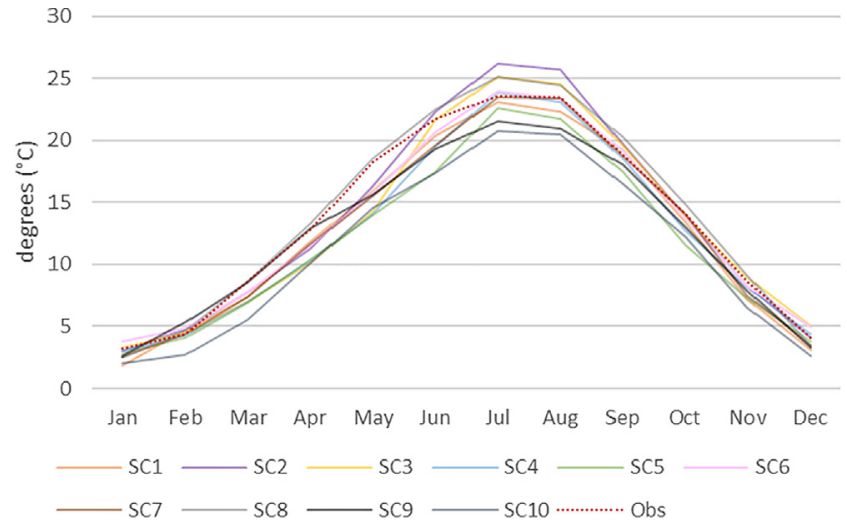

Fig. 3. Mean monthly values of temperature $\left({ }^{\circ} \mathrm{C}\right)$ from the observed data (Obs) and the uncorrected data of the GCM-RCM simulations (SC1 to SC10) for the baseline period 1983-2012.

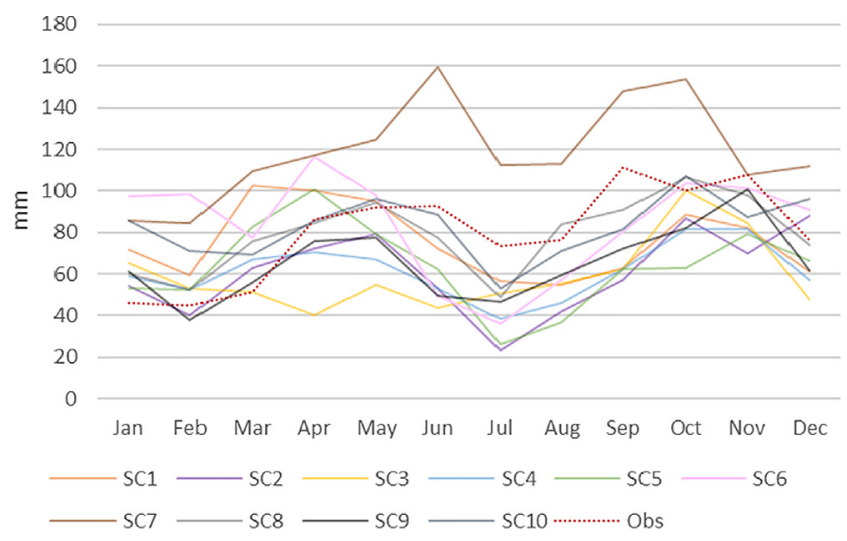

Fig. 4. Mean monthly values of precipitation $(\mathrm{mm})$ from the observed data (Obs) and the uncorrected data of the GCM-RCM simulations (SC1 to SC10) for the baseline period 1983-2012.

caused by the different conceptual or mathematical formulations that each modeling institute decides to use to describes the different climatic processes. Gosling and colleagues (2011) define this uncertainty as "climate model structural uncertainty", meaning that climate projections for a single greenhouse gas emission scenario differ for different GCM-RCM combinations. Being able to identify and quantify the different sources of uncertainty is very important for decision-making processes. In fact, recommendations resulting from a single GCM-RCM combination may be highly uncertain whereas the application of multiple combinations will highlight the scale of uncertainty. In the presence of high uncertainty, decision-makers should rather opt for no-

Table 3

GCM-RCM simulations selected for the study.

\begin{tabular}{|c|c|c|c|c|c|}
\hline & N. Simulations & GCM & RCM & Spatial Resolution & Institute \\
\hline CMCC & SC1 & CMCC-CM Scoccimarro et al. (2011) & CCLM (Rockel et al. (2008) & $0.0715 \mathrm{deg}(8 \mathrm{~km})$ & CMCC \\
\hline \multirow[t]{9}{*}{ EURO-CORDEX } & SC2 & HadGEM2-ES Collins et al. (2011) & RCA4 Strandberg et al. (2014) & $0.11 \mathrm{deg}(12 \mathrm{~km})$ & SMHI \\
\hline & SC3 & IPSL-CM5A-MR Dufresne et al. (2013) & RCA4 Strandberg et al. (2014) & $0.11 \mathrm{deg}(12 \mathrm{~km})$ & SMHI \\
\hline & SC4 & CNRM-CM5 Voldoire et al. (2013) & RCA4 Strandberg et al. (2014) & $0.11 \mathrm{deg}(12 \mathrm{~km})$ & SMHI \\
\hline & SC5 & EC-EARTH Hazeleger et al. (2010) & RCA4 Strandberg et al. (2014) & $0.11 \mathrm{deg}(12 \mathrm{~km})$ & SMHI \\
\hline & SC6 & MPI-ESM-LR (Giorgetta et al. (2013) & RCA4 Strandberg et al. (2014) & $0.11 \mathrm{deg}(12 \mathrm{~km})$ & SMHI \\
\hline & SC7 & CNRM-CM5 Voldoire et al. (2013) & CCLM Rockel et al. (2008) & $0.11 \mathrm{deg}(12 \mathrm{~km})$ & CLMcom \\
\hline & SC8 & HadGEM2-ES Collins et al. (2011) & RACMO22E VanMeijgaard et al. (2008) & $0.11 \mathrm{deg}(12 \mathrm{~km})$ & KNMI \\
\hline & SC9 & EC-EARTH Hazeleger et al. (2010) & HIRHAM5 Christensen et al. (2007) & $0.11 \mathrm{deg}(12 \mathrm{~km})$ & DMI \\
\hline & SC10 & EC-EARTH Hazeleger et al. (2010) & RACMO22E VanMeijgaard et al. (2008) & $0.11 \mathrm{deg}(12 \mathrm{~km})$ & KNMI \\
\hline
\end{tabular}

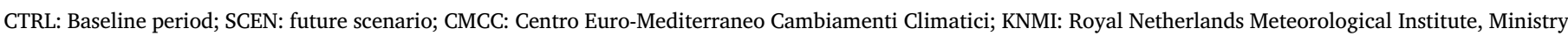

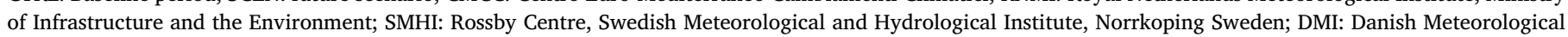
Institute, Copenhagen, Denmark. 

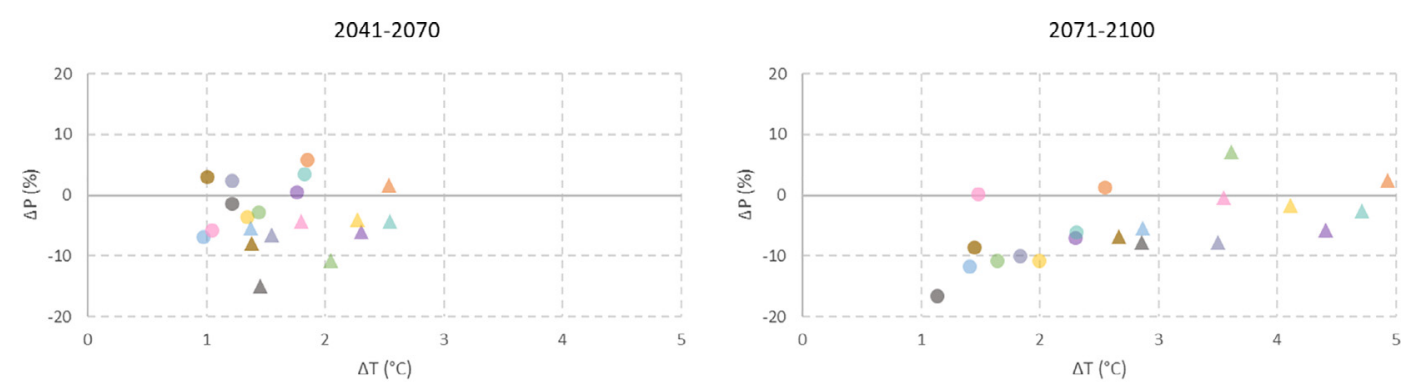

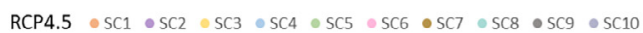

$\mathrm{RCP} 8.5 \Delta \mathrm{SC1} \triangle \mathrm{SC2} \triangle \mathrm{SC} 3 \Delta \mathrm{SC} 4 \Delta \mathrm{SC} 5 \Delta \mathrm{SC6} \Delta \mathrm{SC7} \Delta \mathrm{SC} 8 \Delta \mathrm{SC} \quad \triangle \mathrm{SC} 10$

Fig. 5. Scatter plots of annual temperature and precipitation changes for all GCM-RCM combinations for both RCP4.5 and RCP8.5 scenarios in the mid-century (2041-2070) and late-century (2071-2100) periods compared to the baseline period (1983-2012).

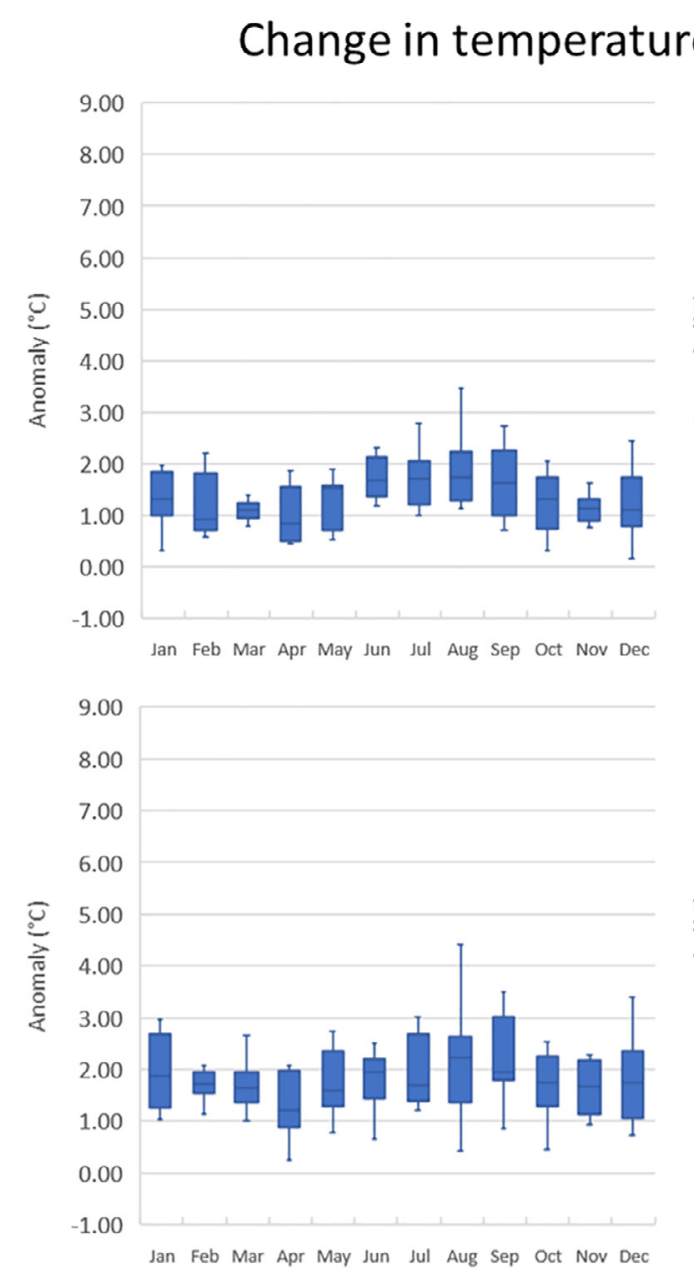

RCP4.5
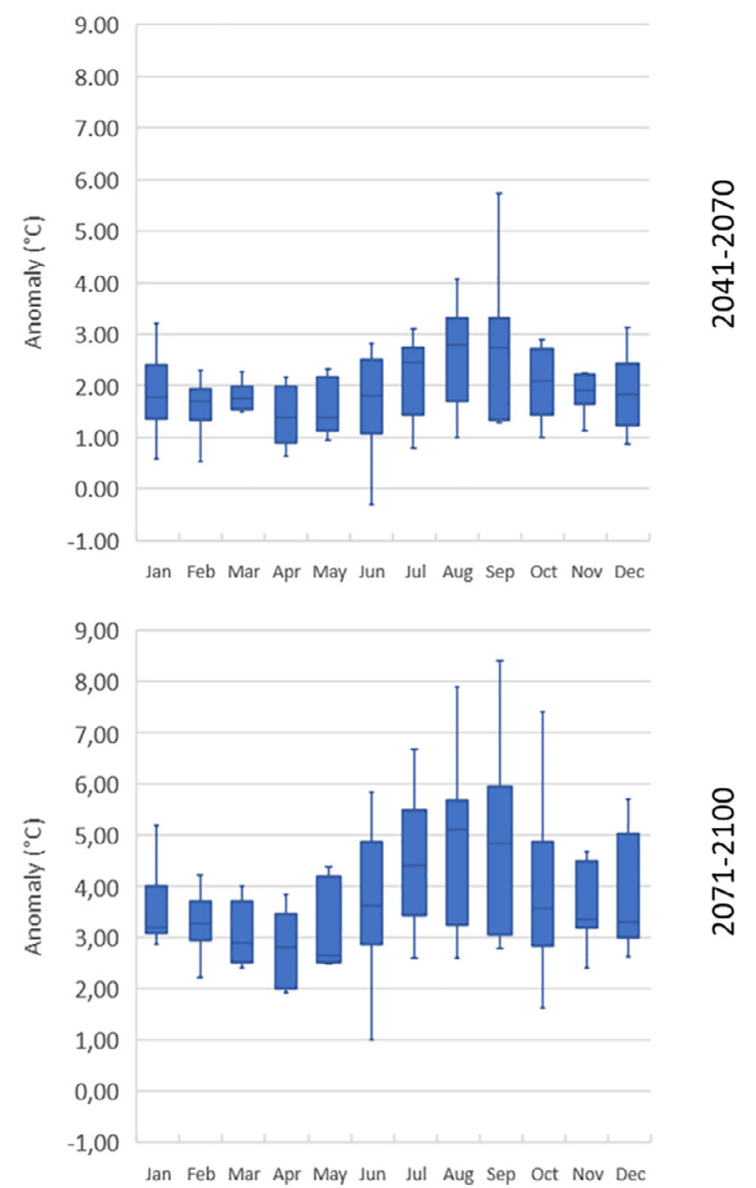

RCP8.5

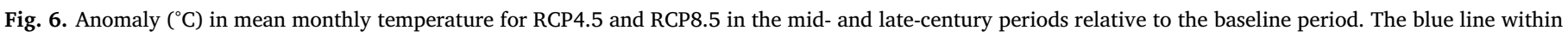

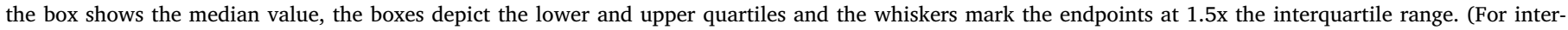
pretation of the references to colour in this figure legend, the reader is referred to the web version of this article.)

regret measures that can yield benefits even in the absence of significant changes in the climate. On the contrary, when multiple models lead to similar environmental changes, more robust decisions can be taken (Teklesadik et al., 2017).

Uncertainty assessment of climate change impacts on hydrology has received much attention in the research community. Studies make use of projections resulting from the adoption of multiple GCMs (Khoi and Hang, 2015), downscaling methods (Joseph et al., 2018), GHGs emission scenarios (Shen et al., 2018), and hydrological models (Teklesadik et al., 2017). However, in an ecosystem management context, what matters is how the biological component might respond to changes in climate and associated abiotic changes in the environment. In this perspective, fewer investigations have been made and the focus has been put mostly on lakes (Mooij et al., 2010).

In this respect, this study investigates the uncertainty of the potential mid- and late-century impacts of climate change on the productivity and community structure of coastal phytoplankton of the hydrological system composed of the Zero River Basin (ZRB) and the 


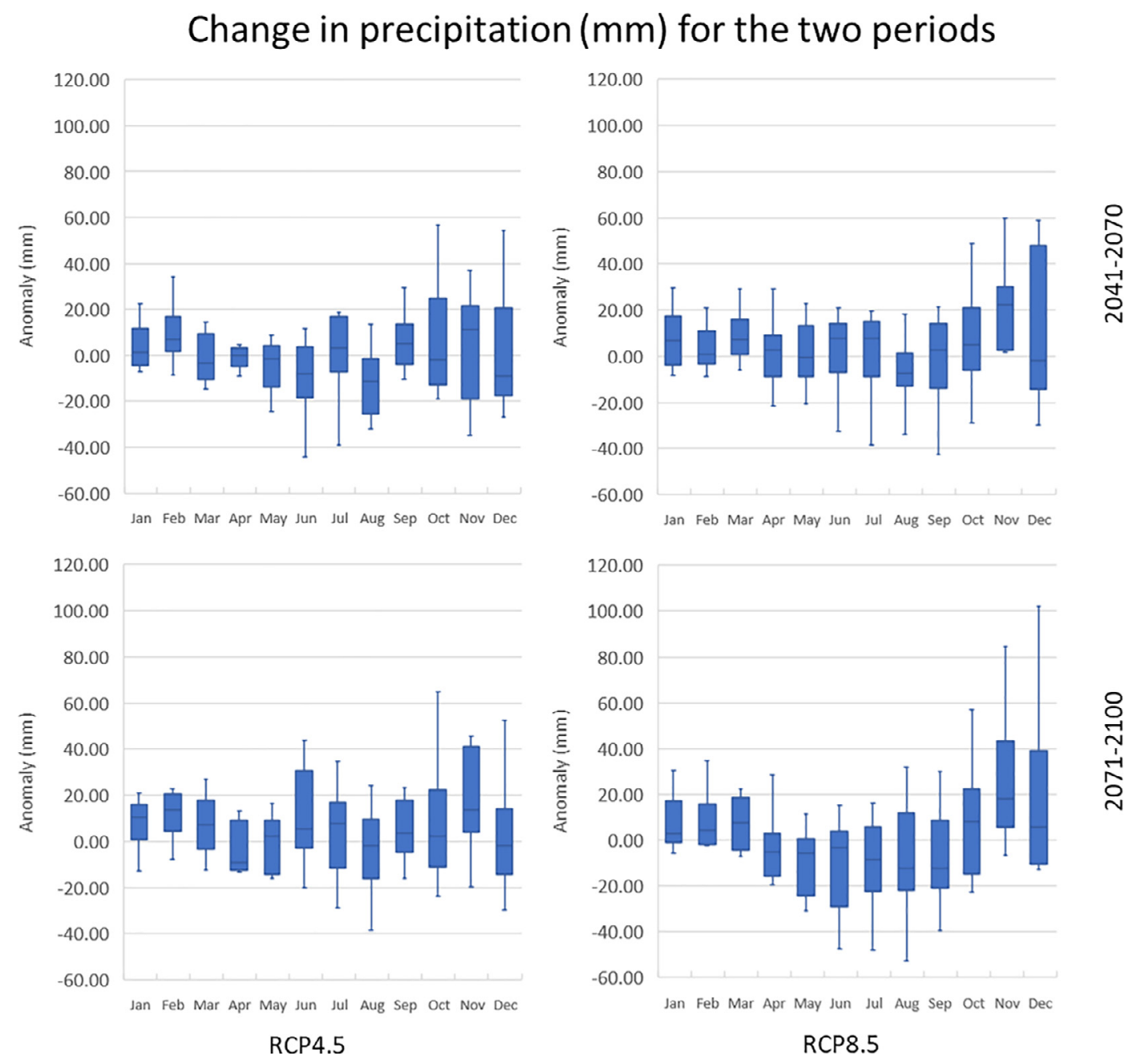

Fig. 7. Anomaly (mm) in mean monthly precipitation for RCP4.5 and RCP8.5 in the mid- and late-century periods relative to the baseline period.

Water discharge (1983-2012)

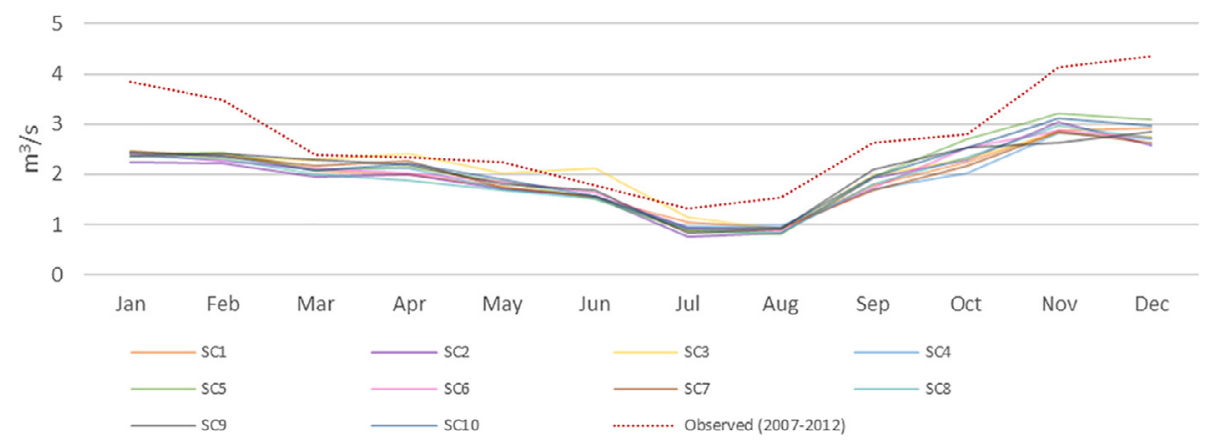

Fig. 8. Comparison between monthly mean of monitored and simulated water discharge values $\left(\mathrm{m}^{3} / \mathrm{s}\right)$.

receiving waters of Palude di Cona (PDC), a shallow waterbody in the lagoon of Venice in Italy. Results are obtained from the application of an ensemble of ten GCM-RCM combinations that drive the hydrological model SWAT (Arnold et al., 1998) and the ecological model AQUATOX (Park et al., 2008). Specifically, we evaluated the uncertainty due to GCM-RCM structure and representative concentration pathway (RCP) scenarios. The paper is structured as follows: a brief description of the case study area is presented in Section 2, followed by a detailed description of method and selected climate change scenarios in Section 3. Section 4 elaborates on the results by analyzing the climatic, hydrologic and ecological changes and their uncertainty. Finally, the paper presents the resulting conclusions in Section 5.

\section{Study area}

The lagoon of Venice, Italy, is one of the most important and studied transitional environment in the world (Cataudella et al., 2015; Guerzoni and Tagliapietra, 2006). This study focuses on the hydrological system composed of the Zero River Basin (ZRB) and the receiving waters of Palude di Cona (PDC), a shallow salt marsh located in the northern part of the lagoon (Fig. 1).

The ZRB extends over a surface area of $140 \mathrm{~km}^{2}$ and has an 


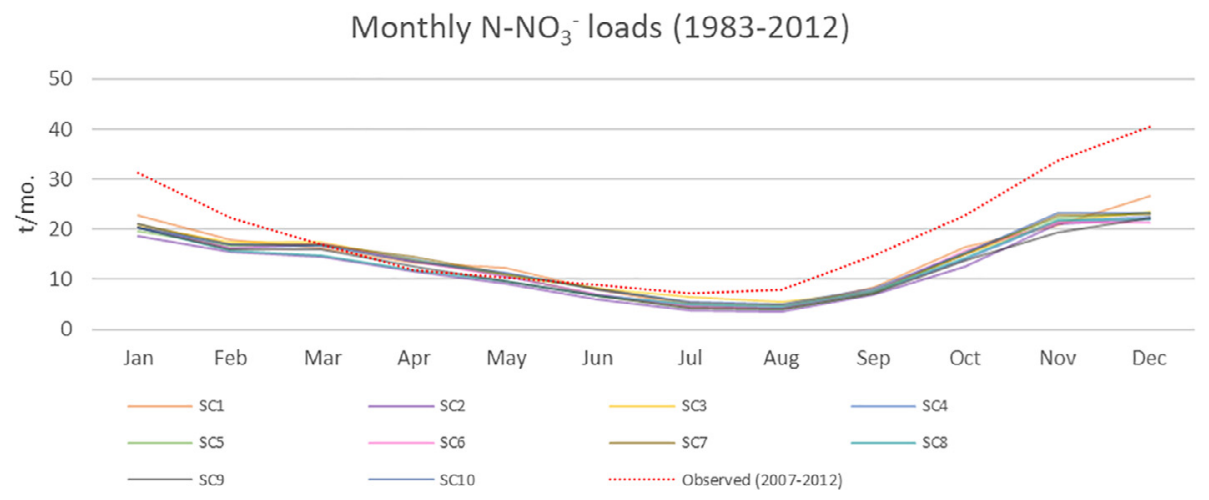

Fig. 9. Comparison between monthly mean of monitored and simulated $\mathrm{N}^{-\mathrm{NO}_{3}}{ }^{-}$loadings ( $\mathrm{t} / \mathrm{mo}$.).

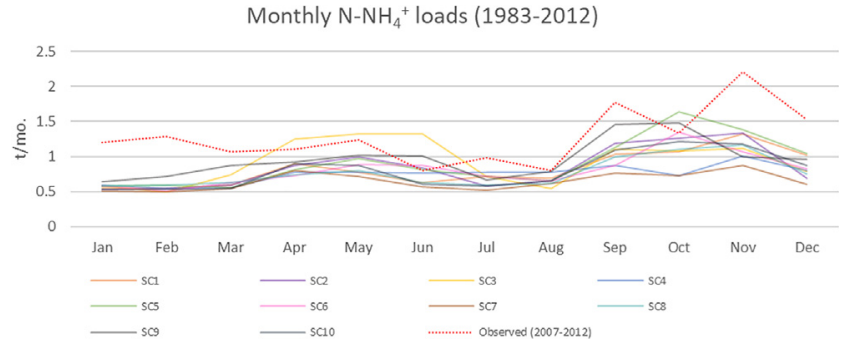

Fig. 10. Comparison between monthly mean of monitored and simulated N$\mathrm{NH}_{4}{ }^{+}$loadings (t/mo.).

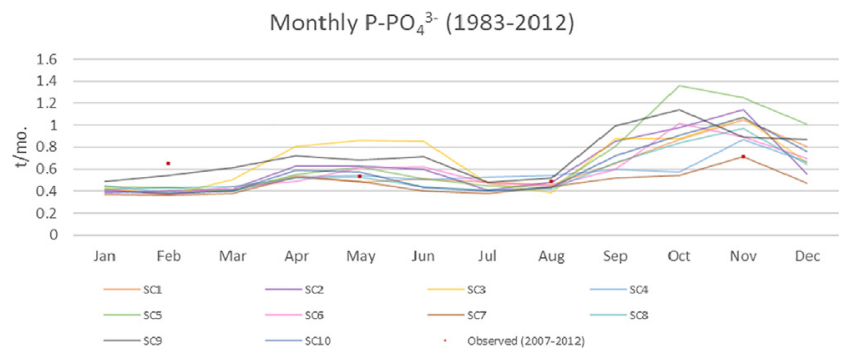

Fig. 11. Comparison between monthly mean of monitored and simulated P$\mathrm{PO}_{4}{ }^{3-}$ loadings ( $\mathrm{t} / \mathrm{mo}$.).

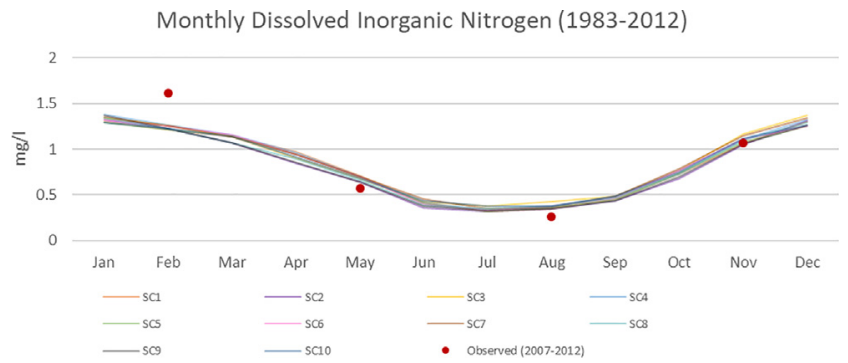

Fig. 12. Comparison between monthly mean of monitored and simulated DIN concentrations $(\mathrm{mg} / \mathrm{l})$.

elevation range that goes from 1 to $110 \mathrm{~m}$ above sea level. The land-use of ZRB is dominated by agricultural activities (72\%), with corn, soy and wheat as dominant crops. The remaining surface is divided into urban and industrial areas (24\%), and semi-natural and forested areas (4\%) (ARPAV, 2009). The ZRB is located within a transitional climatic area between Mediterranean and continental climates featuring cold winters and summers with frequent storms (ARPAV, 2000). From the meteorological observations for the period 2002-2012 (ARPAV, 2013), the yearly average temperature is $14^{\circ} \mathrm{C}$, with January and December being the coldest months $\left(\simeq 4{ }^{\circ} \mathrm{C}\right)$, and July and August the warmest $\left(\simeq 25^{\circ} \mathrm{C}\right)$.

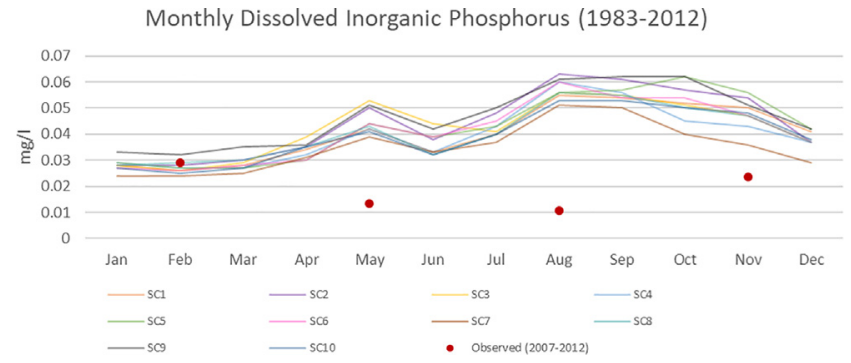

Fig. 13. Comparison between monthly mean of monitored and simulated DIP concentrations (mg/1).

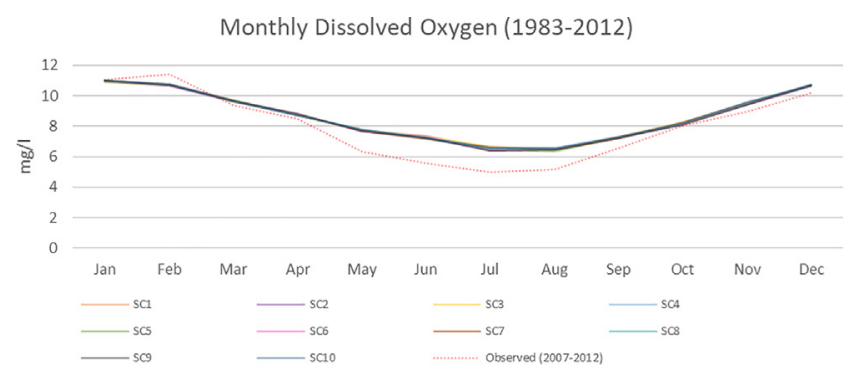

Fig. 14. Comparison between monthly mean of monitored and simulated dissolved oxygen concentrations (mg/l).

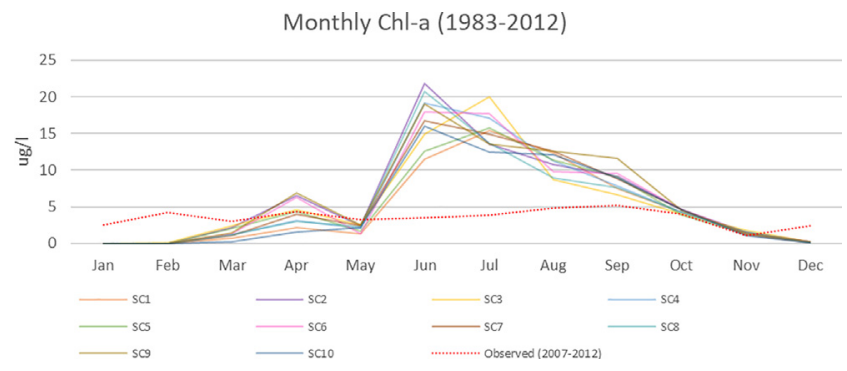

Fig. 15. Comparison between monthly mean of monitored and simulated chl-a concentrations $(\mu \mathrm{g} / \mathrm{l})$.

The yearly average rainfall is $\simeq 1000 \mathrm{~mm}$, with peaks in spring and autumn and minimums in winter and summer.

The PDC is a shallow waterbody positioned in the upper-north basin of the lagoon of Venice and circumscribed by salt-marshes. PDC covers a surface of $3.6 \mathrm{~km}^{2}$ and features an average depth of $0.8 \mathrm{~m}$ during the mean tidal conditions of the microtidal cycle of the lagoon of Venice (Sarretta et al., 2010). From the meteorological observations for the period 2002-2012 (ARPAV, 2013) temperatures are, on average, $0.5-1{ }^{\circ} \mathrm{C}$ warmer than those of the ZRB and yearly precipitations are, on average, $200-300 \mathrm{~mm}$ lower (Guerzoni and Tagliapietra, 2006). The 


\section{Change in discharge $\left(\mathrm{m}^{3} / \mathrm{s}\right)$ for the two periods}
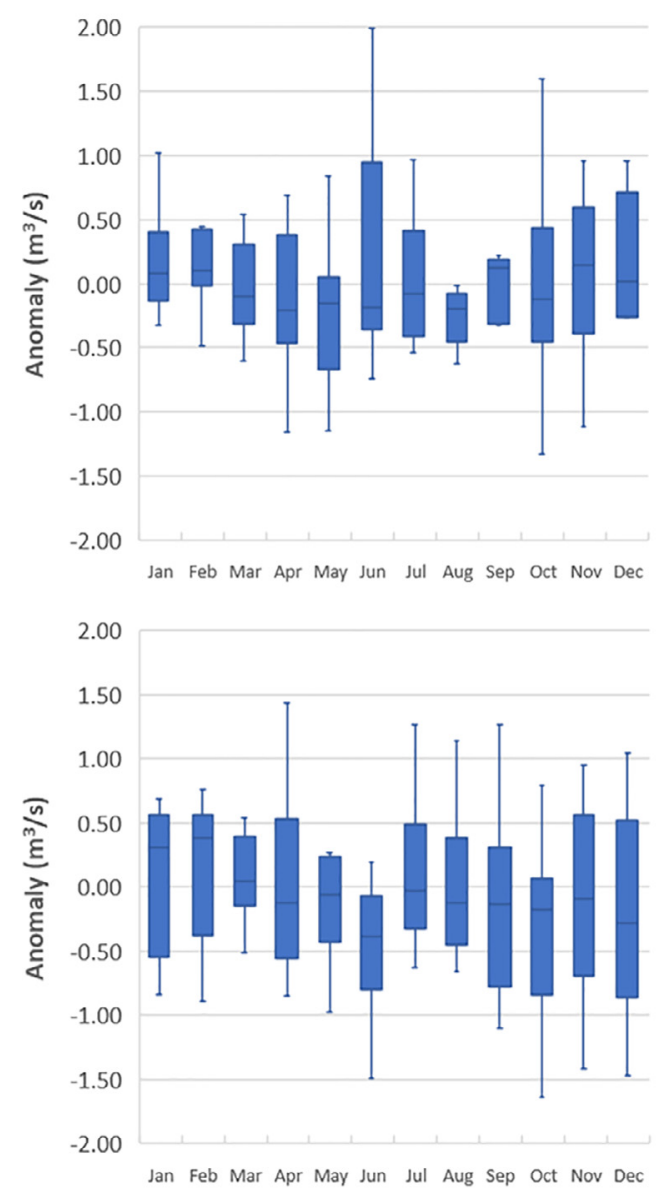

RCP4.5
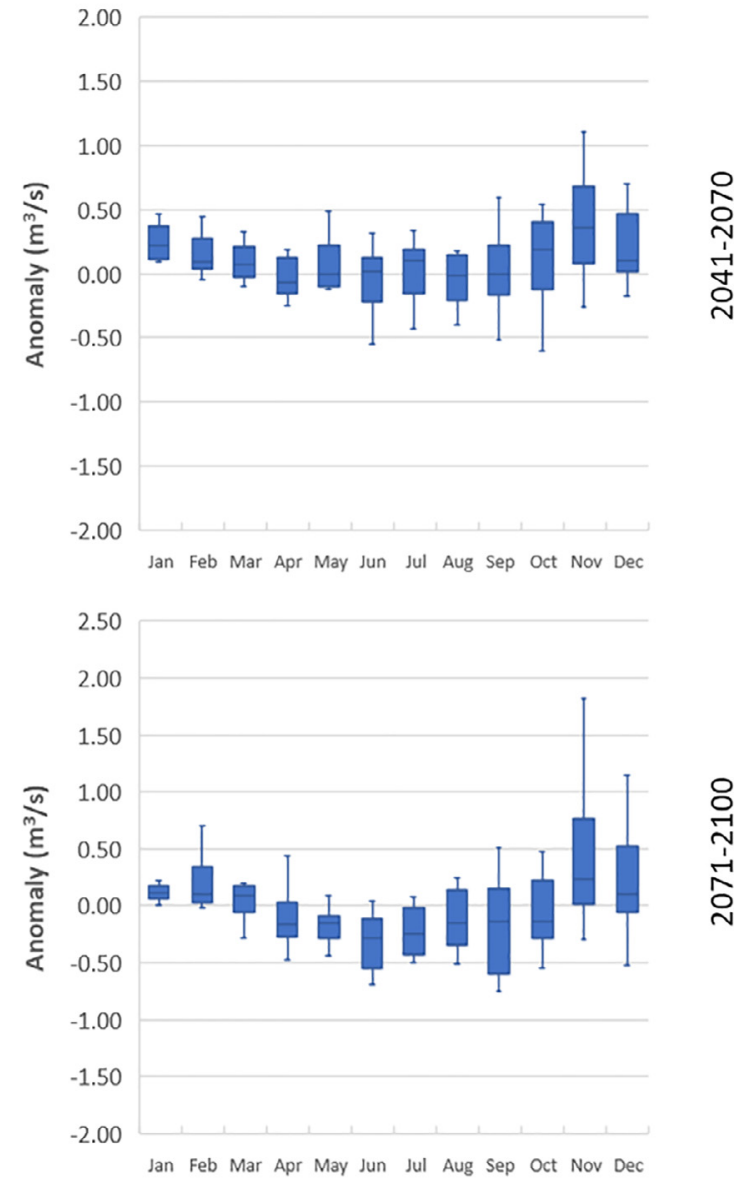

$\mathrm{RCP} 8.5$

Fig. 16. Anomaly $\left(\mathrm{m}^{3} / \mathrm{s}\right)$ in mean monthly discharge for RCP4.5 and RCP8.5 in the mid- and late-century periods relative to the baseline period.

shallow waters of PDC promote rapid equilibrium between air and water temperatures, with the latter showing the highest values in the summer, reaching $26-27^{\circ} \mathrm{C}$, and the lowest values in winter, around $5-7^{\circ} \mathrm{C}$, as indicated by monitoring data for the period 2007-2012 (SAMANET, 2013). Solar radiation reaches the highest peaks (25 MJ/ $\mathrm{m}^{2}$ day) in summer and the lowest $\left(5 \mathrm{MJ} / \mathrm{m}^{2}\right.$ day) in winter (ARPAV, 2013).

The trophic state of PDC follows the classic cycle of aquatic ecosystems in a temperate climate (Facca and Sfriso, 2009; Guerzoni and Tagliapietra, 2006): in winter, primary production is low and nutrient concentrations, which show high values, are mainly controlled by nutrient loading and transport events; in spring, solar radiation triggers the first phytoplankton blooms, which can be further stimulated or inhibited by the availability of nutrients; in summer, nutrient concentrations reach the minimum concentration values and phytoplanktonic blooms reach their peak. In autumn, phytoplankton concentrations progressively decrease to minimum levels of abundance and, consequently, nutrient concentrations start to increase once again. In regard to the fractions of the main phytoplankton groups, PDC is representative of the community structure of the Lagoon of Venice where diatoms represent the dominant group (72\%), followed by flagellates (27\%) and dinoflagellates (1\%) (Guerzoni and Tagliapietra, 2006).

\section{Methods and data}

\subsection{Integrated modelling approach}

To understand the complexity of the interaction between the climate, hydrology and ecosystem of the ZRB-PDC system, we adopted the integrated modelling approach represented in Fig. 2. The approach incorporates: (1) climate simulations generated by coupling of a General Circulation Model (GCM) with a Regional Climate Model (RCM) and by applying the tool CLIME for the downscaling of climate projections; (2) the hydrological model Soil and Water Assessment Tool (SWAT) for the modelling of river basin discharge and nutrient loads; and (3) the ecological model AQUATOX for the modelling of coastal phytoplankton.

This section will focus on the description of the "Climate" module of Fig. 2. For a comprehensive description of the hydrological and ecological modelling with SWAT and AQUATOX, their spatial and temporal input datasets, parameterization, calibration and validation procedures for their application to the ZRB-PDC system, please refer to the study developed and performed by Pesce et al. (2018). Table 1 summarizes the SWAT performance in modeling the hydrology and nutrient loadings of the ZRB, and the AQUATOX performance in modeling the physicochemical and biological properties of PDC.

\subsection{Climate projections}

Climate impact assessment studies require future climate conditions 


\section{Change in $\mathrm{N}-\mathrm{NO}_{3}{ }^{-}$loadings (t/mo.) for the two periods}
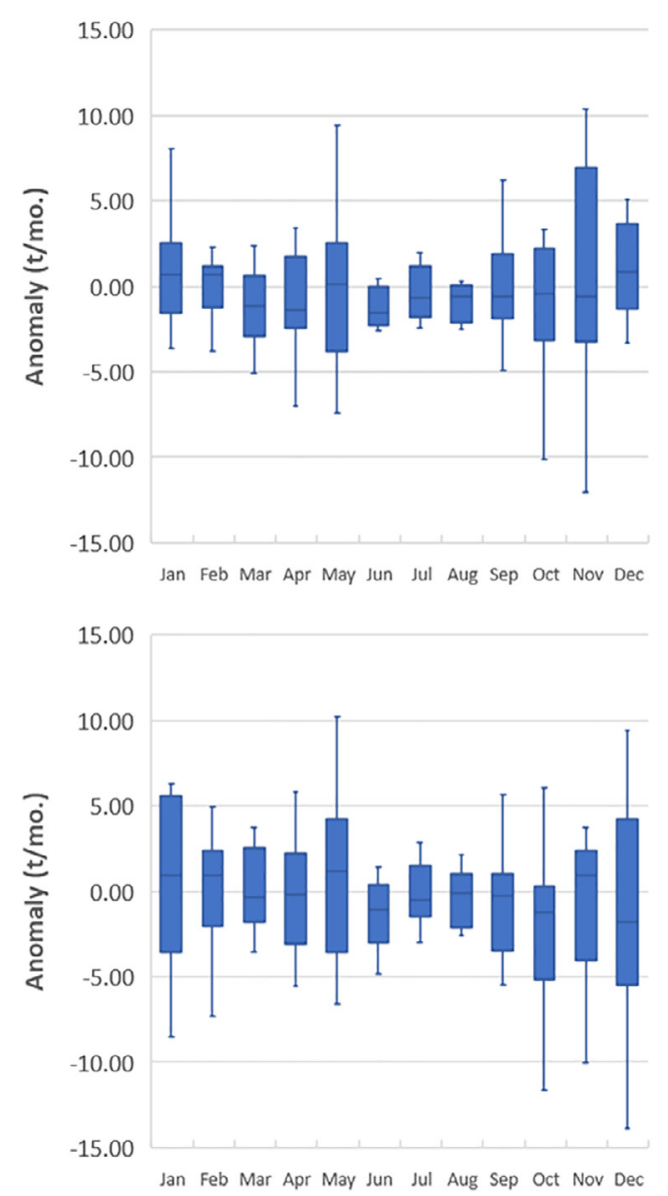

RCP4.5
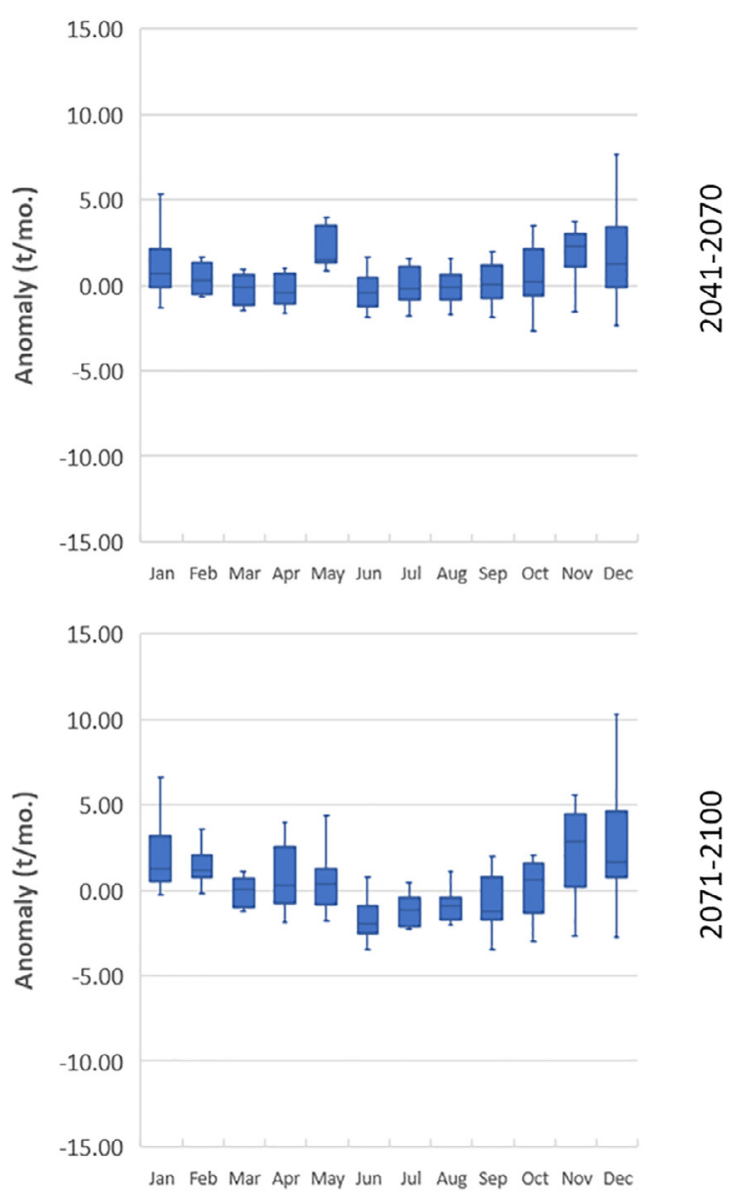

RCP8.5

Fig. 17. Anomaly (t/mo.) in mean monthly ${\mathrm{N}-\mathrm{NO}_{3}}^{-}$loadings for RCP4.5 and RCP8.5 in the mid- and late-century periods relative to the baseline period.

to be translated into potential changes in hydrology, ecology or other aspects- of the examined area. In this study, modelling results for daily maximum and minimum temperature and mean precipitation from a multi-model-ensemble of 10 GCM-RCM combinations for two GHG concentration pathways were employed to provide daily time series for the models SWAT and AQUATOX. Other climate variables such as solar radiation, relative humidity, and wind speed affects hydrological processes and dynamics of phytoplankton. However, expecting that the majority of changes in phytoplankton dynamics and composition will be associated to changes in temperature stratification and nutrient concentrations, which highly depend on temperature and precipitation (Winder and Sommer, 2012), it was decided to focus on changes in these variables while keeping the others equal to the baseline period.

In our analysis, simulation along 30-year time horizons, minimum period length for climatological studies as suggested by the World Meteorological Organization (WTO, 2007), were used to compare midcentury (2041-2070) and late-century (2071-2100) future time frames against the baseline period 1983-2012. For the baseline period, we considered GCM-RCM simulations under the "historical" experiment for the period 1983-2005 and simulations under the RCP4.5 and RCP 8.5 experiments from 2006 to 2012.

Two RCPs were considered: RC4.5 and RCP8.5. The RCP4.5 (Thomson et al., 2011) is a stabilization scenario where emissions peak in 2040 and decline strongly until 2080 by employing technologies and strategies to reduce GHG emissions, thus generating a total radiative forcing of $4.5 \mathrm{Wm}^{-2}$ by 2100 (approximately $650 \mathrm{ppm} \mathrm{CO}_{2}$-equivalent). The RCP8.5 (Riahi et al., 2011) is a business as usual scenario with increasing GHG emissions over time, leading to high GHG concentration levels; it represents a rising radiating forcing pathway leading to $8.5 \mathrm{Wm}^{-2}$ in 2100 (approximately $1370 \mathrm{ppm} \mathrm{CO}_{2}$-equivalent). Table 2 provides a summary of the scenarios adopted in this study. RCP2.6 was not considered because it is not consistently used among climate models (Mora et al., 2013). It also describes a scenario where $\mathrm{CO}_{2}$ peaks by 2020 and is followed by reduced emissions which is considered, according to the current situation and necessary carbon emission reduction and mitigation efforts (IPCC, 2013), as currently unfeasible and no longer achievable (van Vliet et al., 2009). RCP 6.0 was not included as it was not a CMIP5 required simulation (IPCC, 2013), resulting in only a limited number of climate models providing projections under it.

Outputs of nine GCM-RCM combinations were obtained from the EURO-CORDEX project (Jacob et al., 2014). EURO-CORDEX is part of the CORDEX initiative (Giorgi et al., 2009), which has the task to coordinate regional downscaling of CMIP5 project to all terrestrial regions of Earth. The EURO-CORDEX project provides outputs from models that run with two spatial resolutions: $50 \mathrm{~km}(0.44 \mathrm{deg})$ and $12 \mathrm{~km}$ ( $0.11 \mathrm{deg})$. For the current study, the $12 \mathrm{~km}(0.11 \mathrm{deg})$ resolution has been selected. Additionally, outputs for temperature and precipitation resulting from the coupling of the GCM CMCC-CM (Scoccimarro et al., 2011) with the RCM COSMO-CLM (Rockel et al., 2008) under the configuration adapted to the Italian territory (Bucchignani et al., 2016; Cattaneo et al., 2012) were also used. The model combinations and their characteristics are presented in Table 3. 


\section{Change in $\mathrm{N}-\mathrm{NH}_{4}{ }^{+}$loadings (t/mo.) for the two periods}
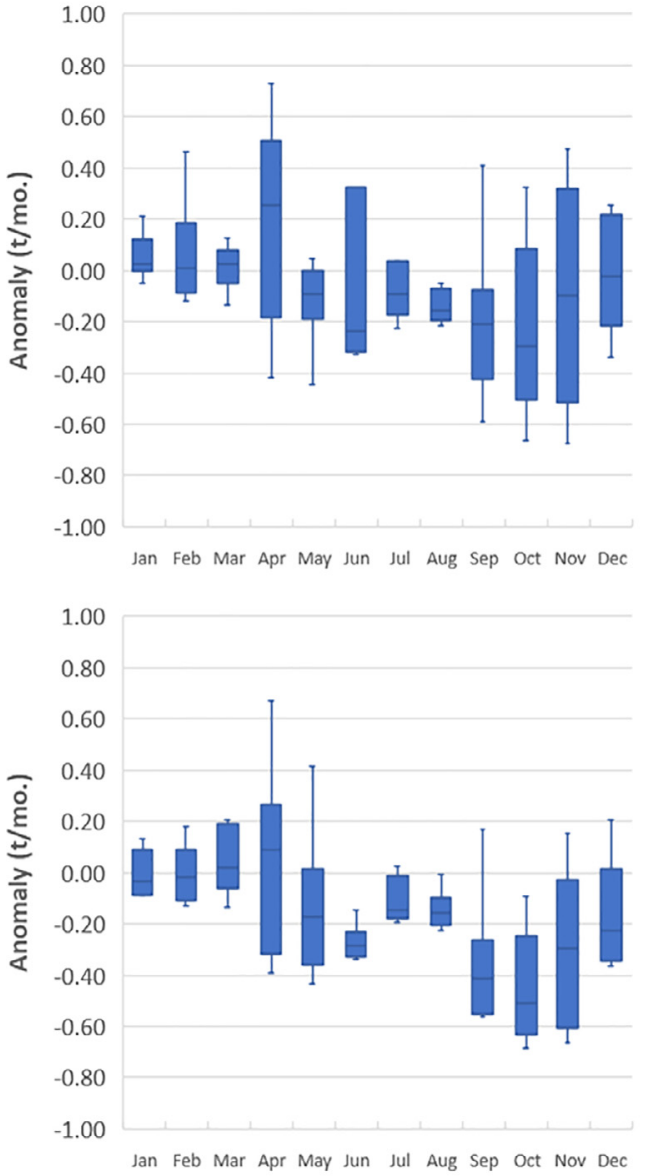

RCP4.5
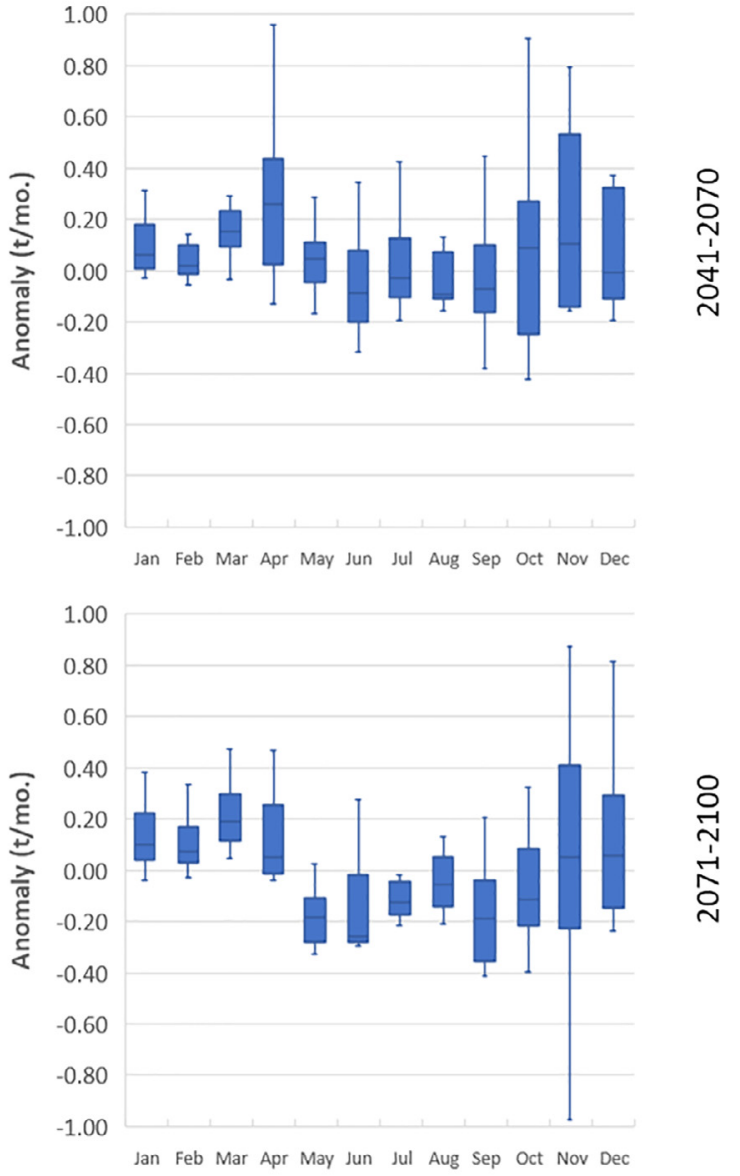

RCP8.5

Fig. 18. Anomaly (t/mo.) in mean monthly ${\mathrm{N}-\mathrm{NH}_{4}}^{+}$for RCP4.5 and RCP8.5 in the mid- and late-century periods relative to the baseline period.

\subsubsection{Bias correction of future climate projections}

RCMs are used to dynamically downscale the output of GCMs. However, biases preventing a proper reproduction of the observed climate conditions persist (Muerth et al., 2013). Consequently, the application of a bias correction method is required to impact models (Teutschbein and Seibert, 2012). In this study, the linear scaling bias correction method (Lenderink et al., 2007) was adopted to correct the output for temperature and precipitation of each GCM-RCM combination. Linear scaling consists in adjusting the mean value by adding a temporally constant offset to the simulated data for temperature, and by multiplying them by a temporally constant correction factor for precipitation, usually at the monthly period. This additive or multiplicative constant (delta) represents the average deviation between the simulated and the observed time series over the baseline period (Hempel et al., 2013). The obtained delta factors were then applied to the daily projections of the two future periods providing bias-corrected values that were used as direct input for SWAT and to serve AQUATOX application. Linear scaling was performed for temperature and precipitation data at each weather station (Castelfranco, Mogliano Veneto, Zero Branco; see Fig. 1) with simulated values in the nearest point from the RCM spatial grid along the baseline period. Figs. 3 and 4 portray, respectively, the mean monthly values of temperature $\left({ }^{\circ} \mathrm{C}\right)$ and precipitation ( $\mathrm{mm}$ ) from the observed data and the uncorrected data of the GCM-RCM simulations for the baseline period 1983-2012. The raw data of simulated projections for temperature show a tendency to underestimate observed data throughout the year (Fig. 3). It can be observed an overestimation for the June-September period for SC2, SC3 and SC8. For precipitation, January, February and March are overestimated by all simulations, with the exception of SC2 and SC9 in February (Fig. 4). In the remaining months the situation is reversed, with an underestimation in all the GCM-RCM uncorrected output. The only exception is represented by the simulation SC7 which overestimate the observed values throughout the whole year.

\subsection{Uncertainty analysis}

Within the uncertainty analysis, the mean monthly climate (precipitation and temperature), hydrological (water discharge, inorganic nitrogen and phosphorus loadings) and ecological parameters (dissolved oxygen, DO, dissolved inorganic nitrogen, DIN, and phosphorus, DIP, Chl-a concentration, diatoms and cyanobacteria concentration) in the mid-century (2041-2070) and late-century (2071-2100) simulated periods were compared against the baseline period (1983-2012). Uncertainties in projected climate, hydrological and ecological changes due to the application of an ensemble of 10 GCM-RCM couples for two different RCPs scenarios were quantified. To calculate the uncertainties, the projected changes in mean monthly values were calculated for each scenario. Box and whiskers plots were used to describe the distribution of monthly values, where the blue lines show the median values, the boxes depict the lower and upper quartiles and the whiskers mark the endpoints at $1.5 \times$ the interquartile range (see Fig. 6 as example). 


\section{Change in $\mathrm{P}_{-} \mathrm{PO}_{4}{ }^{3-}$ loadings ( $\mathrm{t} / \mathrm{mo}$.) for the two periods}

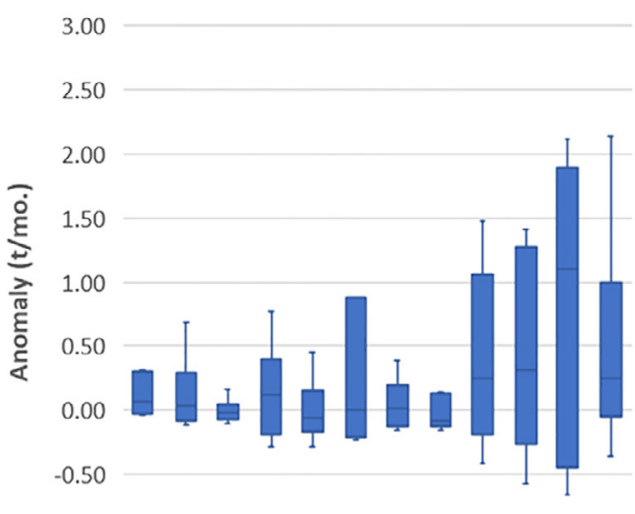

$-1.00$

Jan Feb Mar Apr May Jun Jul Aug Sep Oct Nov Dec

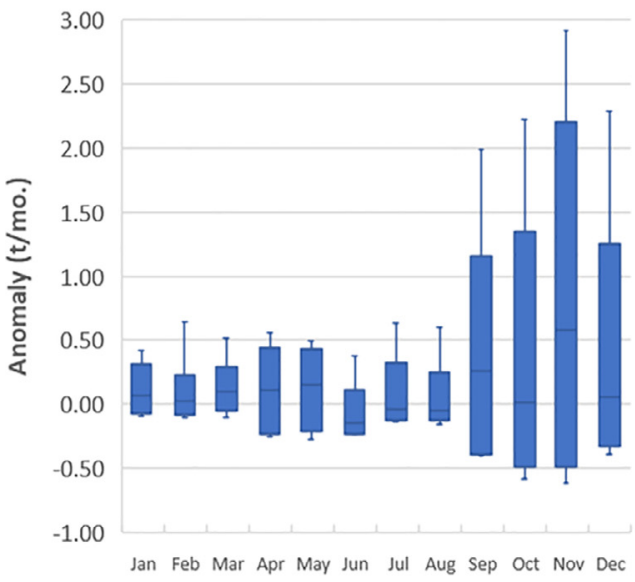

RCP4.5
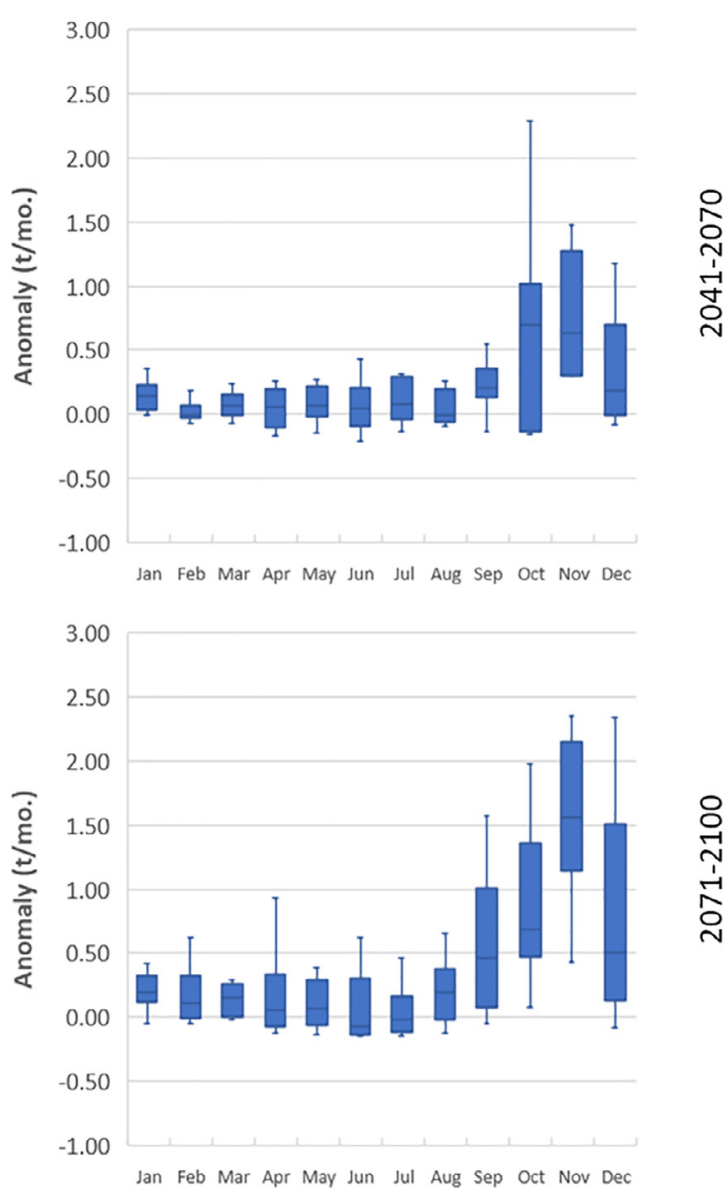

RCP8.5

Fig. 19. Anomaly (t/mo.) in mean monthly $\mathrm{P}_{-} \mathrm{PO}_{4}{ }^{3-}$ for RCP4.5 and RCP8.5 in the mid- and late-century periods relative to the baseline period.

\section{Results and discussion}

\subsection{Climate change projections}

The scatter plot of Fig. 5 shows the mean precipitation deltas $(\Delta \mathrm{P})$ as a function of the mean temperature deltas $(\Delta \mathrm{T})$ for each GCM-RCM projection for the mid- (2041-2070) and late-century (2071-2100) periods compared to the baseline period (1983-2012). As expected, and in agreement with the findings of previous studies (Tomozeiu et al., 2014; Zollo et al., 2016), the annual temperature showed a univocal increasing trend among all the projections. The spread of temperature projections is smaller for the mid-century period $\left(0.97-2.55^{\circ} \mathrm{C}\right)$ compared to the late-century $\left(1.13-4.93{ }^{\circ} \mathrm{C}\right)$. In the mid-century period, all RCP4.5 projections show an expected increase that goes not above $2^{\circ} \mathrm{C}$, while five RCP8.5 projections go beyond that value. In the late-century period, RCP4.5 projections show a slight increase from the mid-century period $\left(+0.44^{\circ} \mathrm{C}\right)$, while RCP8.5 projections display a larger increase of $\left(+1.8^{\circ} \mathrm{C}\right)$. Projections for precipitation show an unclear tendency, especially in the mid-century period. Mid-century projections show significant discrepancies among the GCM-RCM models, indicating a change within the range of $-14.9 \%$ to $+5.9 \%$. Five RCP4.5 projections suggest an increase in precipitation from $+0.6 \%$ to $+5.9 \%$, while the other five show a decrease between $-1.2 \%$ and $-6.7 \%$. Only one RCP8.5 projection show an increase in precipitation $(+1.6 \%)$, while the other nine display a decrease from $-3.9 \%$ to $-14.9 \%$. Projections for the late-century period show a more defined trend, with most projections indicating a reduction in precipitation between $-0.4 \%$ and
$-16.5 \%$. Only four projections predict a slight increase in precipitation, from $+0.3 \%$ to $+7.2 \%$.

Projected monthly changes of temperature and precipitation are observable in all future scenarios when compared to the baseline period (see Table 2). However, not all months show the same pattern of change. Fig. 6 displays the monthly change in temperature obtained from the monthly values representative of the baseline period compared to the monthly values of the ten projections. In the mid-century period, the medians of the simulated temperature changes show shifts from the reference mean temperature from $+0.9^{\circ} \mathrm{C}$ (April, RCP4.5) to $+2.8^{\circ} \mathrm{C}$ (August, RCP8.5). In the late-century period, the median shifts from $+1.2{ }^{\circ} \mathrm{C}$ (April, RCP4.5) to $+5.1{ }^{\circ} \mathrm{C}$ (August, RCP8.5). For each scenario, the greatest increase is observed during the months of July, August and September. Projections for RCP4.5 show a higher level of agreement when compared to those for RCP8.5. The greatest discrepancies among projections are observable in the late-century period of the RCP8.5 scenarios, where projections for the months from June to October shift from a minimum of $+1.01^{\circ} \mathrm{C}$ (June) to a maximum of $+8.41{ }^{\circ} \mathrm{C}$ (September).

Fig. 7 illustrates the monthly change in precipitation obtained from the monthly values representative of the baseline period compared to the monthly values of the 10 projections. The general trend of the four scenarios shows an increase in the late autumn-winter period and a decrease in the late spring-summer period. Specifically, in the midcentury, the medians of the simulated precipitation changes show shifts from the reference mean precipitation from $-11.6 \mathrm{~mm}$ (August, RCP4.5) to $+22.4 \mathrm{~mm}$ (November, RCP8.5). In the late-century period, 


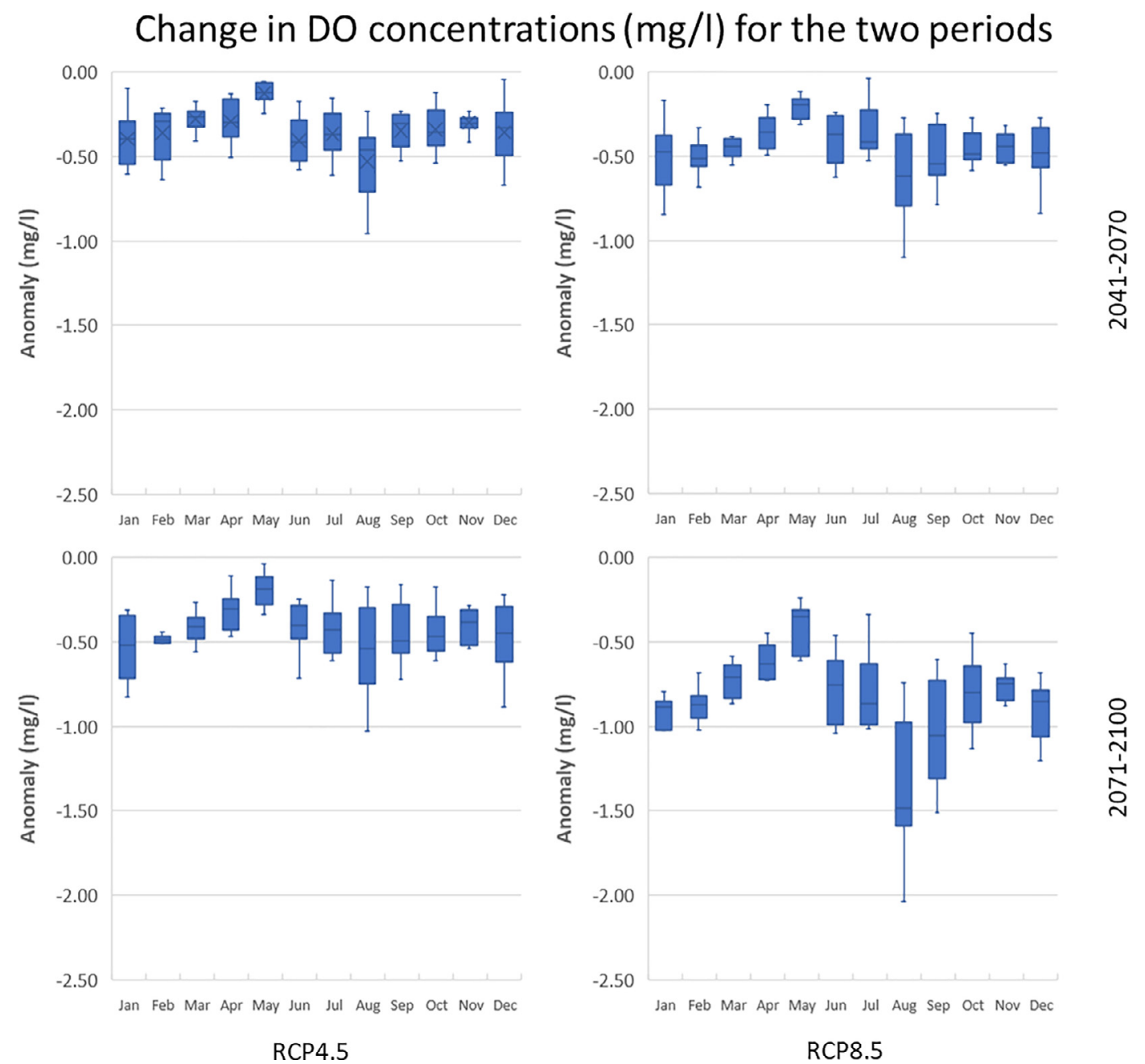

Fig. 20. Anomaly (mg/l) in mean monthly dissolved oxygen for RCP4.5 and RCP8.5 in the mid- and late-century periods relative to the baseline period.

the median shifts from $-12.3 \mathrm{~mm}$ (August, RCP8.5) to $+18.1 \mathrm{~mm}$ (November, RCP8.5). The level of agreement is similar for both RCP4.5 and RCP8.5 scenarios. Projections show a higher level of agreement in the first semester, while the second part of the year is characterized by higher discrepancies.

\subsection{Comparison between monitored and simulated hydrologic and ecological parameters in the baseline period}

A graphic comparison between monitored and simulated values of selected hydrological and ecological parameters is presented in Figs. 8-15. Daily monitored data for the period 2007-2012 were available for the water flow and nitrogen loadings $\left(\mathrm{N}_{-} \mathrm{NO}_{3}{ }^{-}, \mathrm{N}_{-} \mathrm{NH}_{4}{ }^{+}\right)$ of ZRB, and for the dissolved Oxygen (DO) and Chl-a characterizing PDC. Seasonal values for the period 2007-2011 were available for phosphorus loadings $\left(\mathrm{P}_{-} \mathrm{PO}_{4}{ }^{3-}\right)$ of $\mathrm{ZRB}$ and for dissolved Inorganic nitrogen (DIN) and phosphorus (DIP) in PDC. Figures compare monthly means of monitored values with monthly means of the projections during the baseline period 1983-2012.

In terms of water discharge from the ZRB flowing into PDC, the projections for the baseline period show agreement throughout the year. Projections are in agreement with observed values in the spring months but are underestimated in summer and winter (Fig. 8). This underestimation also affects late autumn-winter projections of $\mathrm{N}^{-\mathrm{NO}_{3}}{ }^{-}$ (Fig. 9) and $\mathrm{N}_{-} \mathrm{NH}_{4}{ }^{+}$(Fig. 10). Finally, $\mathrm{P}^{-\mathrm{PO}_{4}}{ }^{3-}$ projections are underestimated in the late-winter period and overestimated in autumnearly winter. In spring and summer projections are in good agreement with observed data (Fig. 11).

With regard to PDC, projections of DIN are in good agreement with observed seasonal data (Fig. 12). Differently, DIP is overestimated in all seasons except for the winter months (Fig. 13). Regarding DO, all projections are in agreement with each other and slightly overestimate observed data in the late spring-summer season (Fig. 14). Finally, future projections of Chl-a feature an observable variability. Specifically, projections underestimate Chl-a concentrations in the months of December and January, and overestimate concentrations in the summer months (Fig. 15).

\subsection{Hydrological responses to climate change}

Hydrology of ZRB is influenced by changes in climate conditions. As a result, nutrient loadings in the Zero river are also affected. Here, variability of water discharge and nutrient loadings are analyzed. In general, future water discharge, as projected by climate models, is on the verge of decreasing during the spring-summer period and increasing during the autumn-winter period. Differences are observable among RCP4.5 and RCP8.5 scenarios, where water discharge simulated projections show lower agreement for RCP4.5 for both mid- and late-century periods when compared to those of RCP8.5 (Fig. 16). These results are consistent with temperature (Fig. 6) and precipitation (Fig. 7) projections, which respectively display an increase in summer temperature with a consequent increase in evapotranspiration, coupled with an increase of precipitation in winter and a reduction in summer. Results conform to other studies concluding that water discharge of 


\section{Change in DIN-DIP ratio for the two periods}
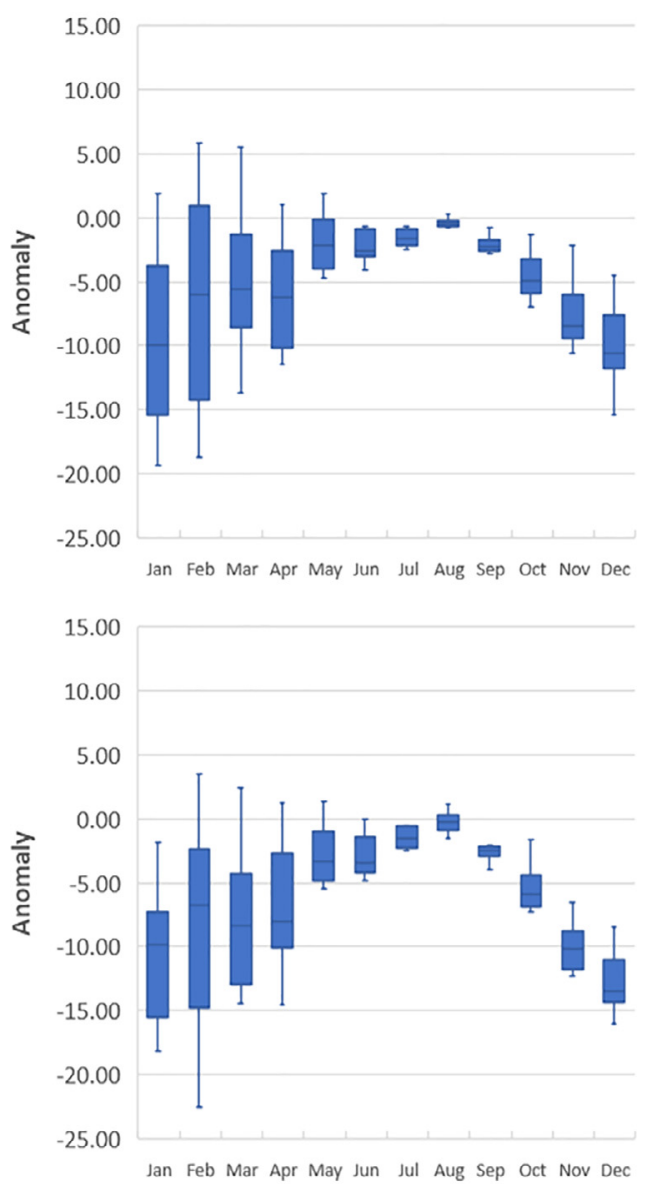

RCP4.5
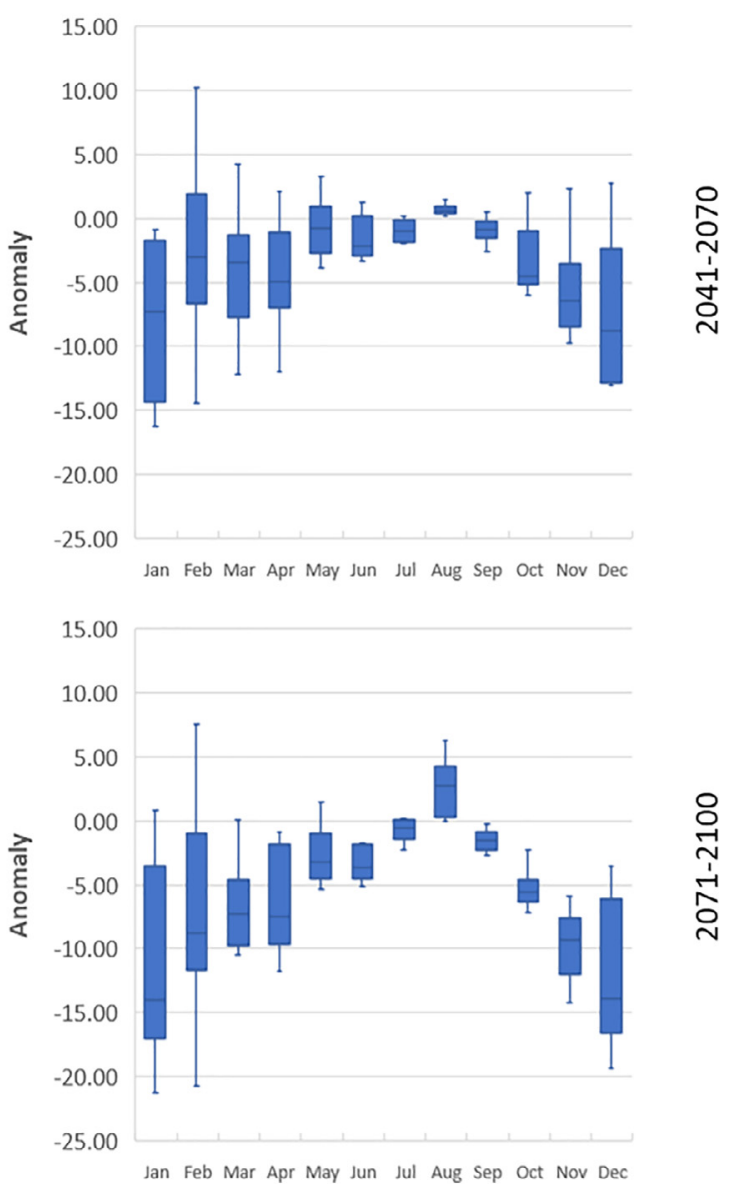

$\mathrm{RCP} 8.5$

Fig. 21. Anomaly in the mean monthly DIN-DIP ratio for RCP4.5 and RCP8.5 in the mid- and late-century periods to the baseline period.

rivers in the future will be taken on an extreme level, with increase in the winter-rainy period and decrease in summer-dry period (Cervi et al., 2018; Pandey et al., 2019; Radchenko et al., 2017). RCP4.5 scenarios, both in mid- and late-century periods, feature a greater uncertainty compared to RCP8.5. The greatest variability among projections takes place in the two rainy periods, spring and autumn-early winter. This can be explained by the fact that climate models have intrinsically more uncertainty during wet days, compared to dry days, due to different simulation models for precipitation (Aryal et al., 2018).

Changes in climate and consequent modifications in hydrological regimes are reflected on nutrient loadings (Chang et al., 2001; Jeppesen

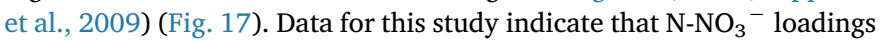
projections are consistent with water discharge in each scenario (R2 > 0.7). Accordingly, RCP4.5 projections reflect the large variability of water discharge simulations when compared to RCP8.5 scenarios. Observing median values, mid-century projections show a slight decrease in summer loadings for both RCP4.5 $(-12 \%)$ and RCP8.5 $(-2 \%)$, and a slight increase in winter for both RCPs $(+4 \%)$. Latecentury projections feature a similar behavior for RCP4.5, with a slight reduction in summer $(-5 \%)$ and a small increase in winter $(+1 \%)$. Differently, late-century RCP8.5 projections portray a more evident decrease of loadings in summer $(-20 \%)$ and increase in winter $(+7 \%)$.

Changes in a N-NH${ }_{4}{ }^{+}$loadings over the modeled time period are observable for both RCP4.5 and RCP8.5 in Fig. 18. Median values for the mid-century period of RCP4.5 feature an increase $(+8 \%)$ in the spring months, a consistent decrease in summer $(-22 \%)$ and autumn $(-18 \%)$, and a slight increase $(+1 \%)$ in winter. RCP8.5 displays more marked changes in the spring season, with an increase in loadings of $+20 \%$. Summer decrease is in line with RCP4.5 projections $(-11 \%)$, while autumns shows the biggest difference among the two RCPs, with RCP8.5 displaying an $+3 \%$ increase. Winter projections indicate a slight increase $(+4 \%)$. Greater mid-century loadings of $\mathrm{N}_{-} \mathrm{NH}_{4}{ }^{+}$for the month of April when compared to late-century projections can be explained by the role of soil water content and soil temperature in the nitrogen dynamics of nitrogen (e.g. mineralization, nitrification, and volatilization). These processes reach their optimal values within a range of temperature and humidity in the soil (Hedin et al., 1998).

$\mathrm{P}^{-} \mathrm{PO}_{4}{ }^{3-}$ loadings show a marked increase in all scenarios during the autumn-early winter period (Fig. 19). Median values for the period from September to December indicate an increase of inorganic phosphorus loading from $48 \%$ to $53 \%$ in the mid-century, and from $28 \%$ to $98 \%$ in the late-century period. This is caused by the intensification of leaching and erosion processes caused by an increased in the precipitation. Also, projected drier summers can increase the erosion in the autumn season by contributing to soil structure breakdown, and consequently increase the runoff of sediments and adsorbed inorganic phosphorus. Finally, SWAT projections show an increase of inorganic phosphorus concentration in the topsoil (Pesce et al., 2018), which can be attributed by an over-fertilization and by accelerated mineralization and sorption to clay particles due to higher temperatures, as also reported in previous studies such as Jennings et al. (2009). A marked variability among projections is observed in the autumn-early winter period and can be attributed to variability characterizing precipitation (see Fig. 7). 


\section{Change in Chl-a $(\mu \mathrm{g} / \mathrm{l})$ for the two periods}
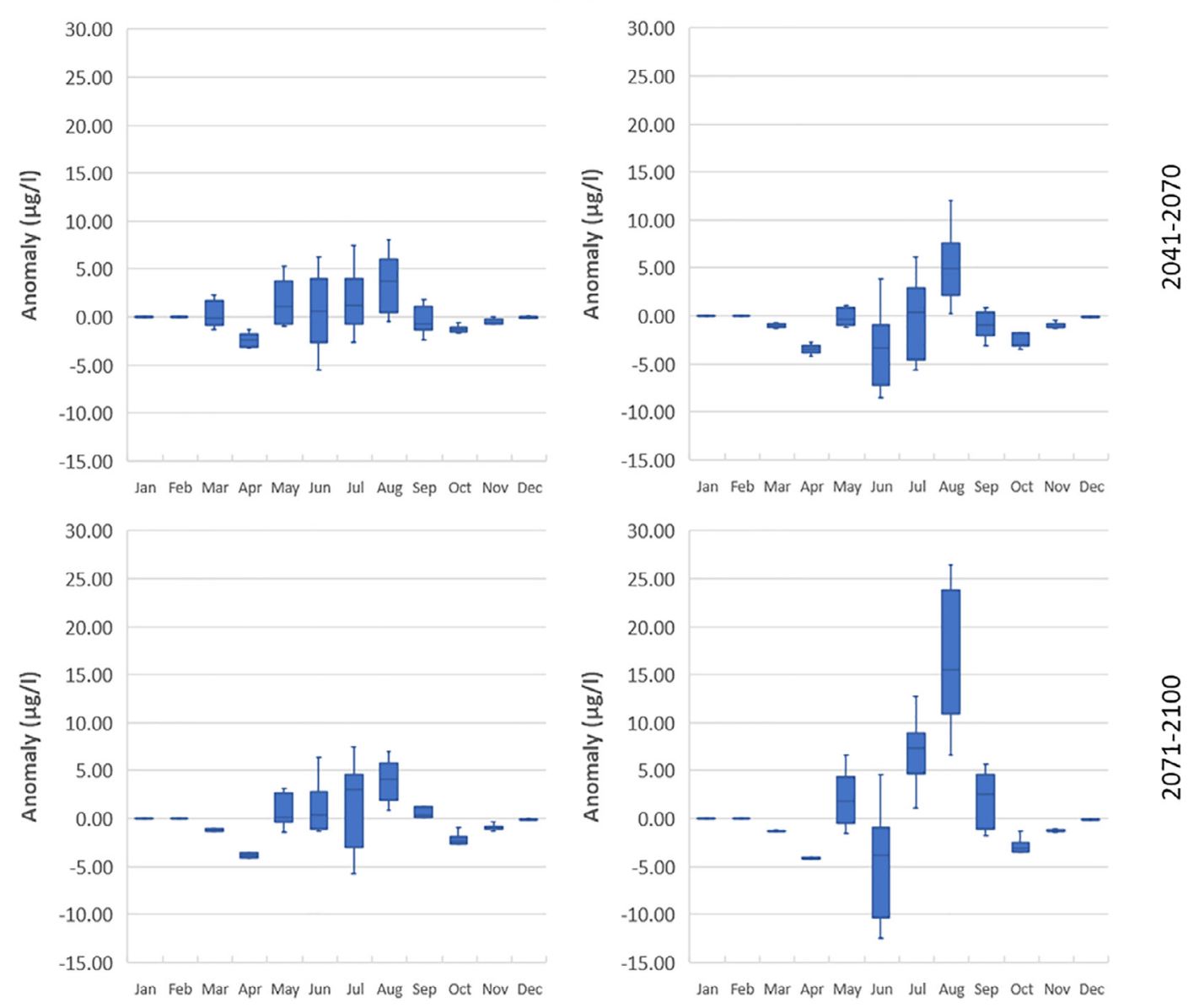

RCP4.5

RCP8.5

Fig. 22. Anomaly $(\mu \mathrm{g} / \mathrm{l})$ in mean monthly chl-a for RCP4.5 and RCP8.5 in the mid- and late-century periods relative to the baseline period.

\subsection{Ecological responses to climate change}

Parameters describing the ecology of PDC are subject to the variability of ZRB loadings and of climate conditions. In terms of DO, all scenarios indicate a reduction throughout the entire year, with peaks in the summer period (Fig. 20). Median values in the month of August project a reduction between 7 and $10 \%$ in the mid-century and between 8 and $23 \%$ in the late-century period. The diminishing concentration of DO can be attributed to the projected rise in air and water temperatures, which diminishes the solubility of oxygen (Schmidtko et al., 2017).

Mid-century projections indicate agreement among each other for both RCP4.5 and RCP8.5. In the late-century period, RCP8.5 displays a greater variability, especially in the months of August and September. This variability reflects the variability the can be observed in summer air temperatures for RCP8.5. This is made even more evident by the shallow nature of PDC, which promotes a rapid temperature equilibrium between water and air.

In terms of DIN-DIP ratio, projections for all scenarios portray a marked decrease in the autumn-winter period, and a slight decrease to slight increase in spring-summer (Fig. 21). Median values for the November-February period show a reduction of $23-39 \%$ of the ratio. Summer months are projected to undergo a reduction of the ratio between 22 and 9\% for three scenarios, while in the RCP8.5 late-century scenario a slight increase of the ratio (2\%) is projected. Future projections of DIN-DIP ratio in PDC are an answer to the increase in DIP concentrations in autumn and winter, which have as an effect the diminishing of the DIN-DIP ratio. Higher variability is shown in the winter-early spring months, while summer and autumn display agreement among projections. This behavior can be associated to the uncertainty related to the nutrient loadings from ZRB. By observing the results, it can be inferred that the events in which nitrogen become the limiting nutrient may increase in frequency, as indicated by other studies on the lagoon of Venice (Zirino et al., 2016).

Regarding Chl-a concentrations, both RCP4.5 and RCP8.5 project an increase in summer of total phytoplankton biomass concentrations throughout the century (Fig. 22). The observed reduction in the month of April that brings to the disappearance of the spring peak typical of the lagoon of Venice is caused by the extinction in PDC of the representative diatom species for that period (see Pesce et al., 2018, Fig. 20). In the late-century, a shift in the summer peak of Chl-a can also be observed. In the RCP4.5 scenario the peak shifts from June to July, while for RCP8.5 it is shifted to August.

The observed variability in Chl-a can be attributed mostly to changes in nutrient concentrations, especially in DIP. Variability among projections is observable only in summer, as winter months feature an extremely low abundance of phytoplankton.

Finally, the variability among projections of diatom and cyanobacteria is illustrated in Fig. 23. First, it can be observed that for each scenario projections agree in portraying a decrease in diatom and an increase in cyanobacteria concentrations during the summer-early autumn period. In the period June-August, median values indicate a diatom decrease of $74-98 \%$ and cyanobacteria increase from $421 \%$ to $3590 \%$. Such high values are justified by the great decrease of diatoms 


\section{Change in Diatoms and Cyanobacteria $(\mu \mathrm{g} / \mathrm{l})$ for the two periods}
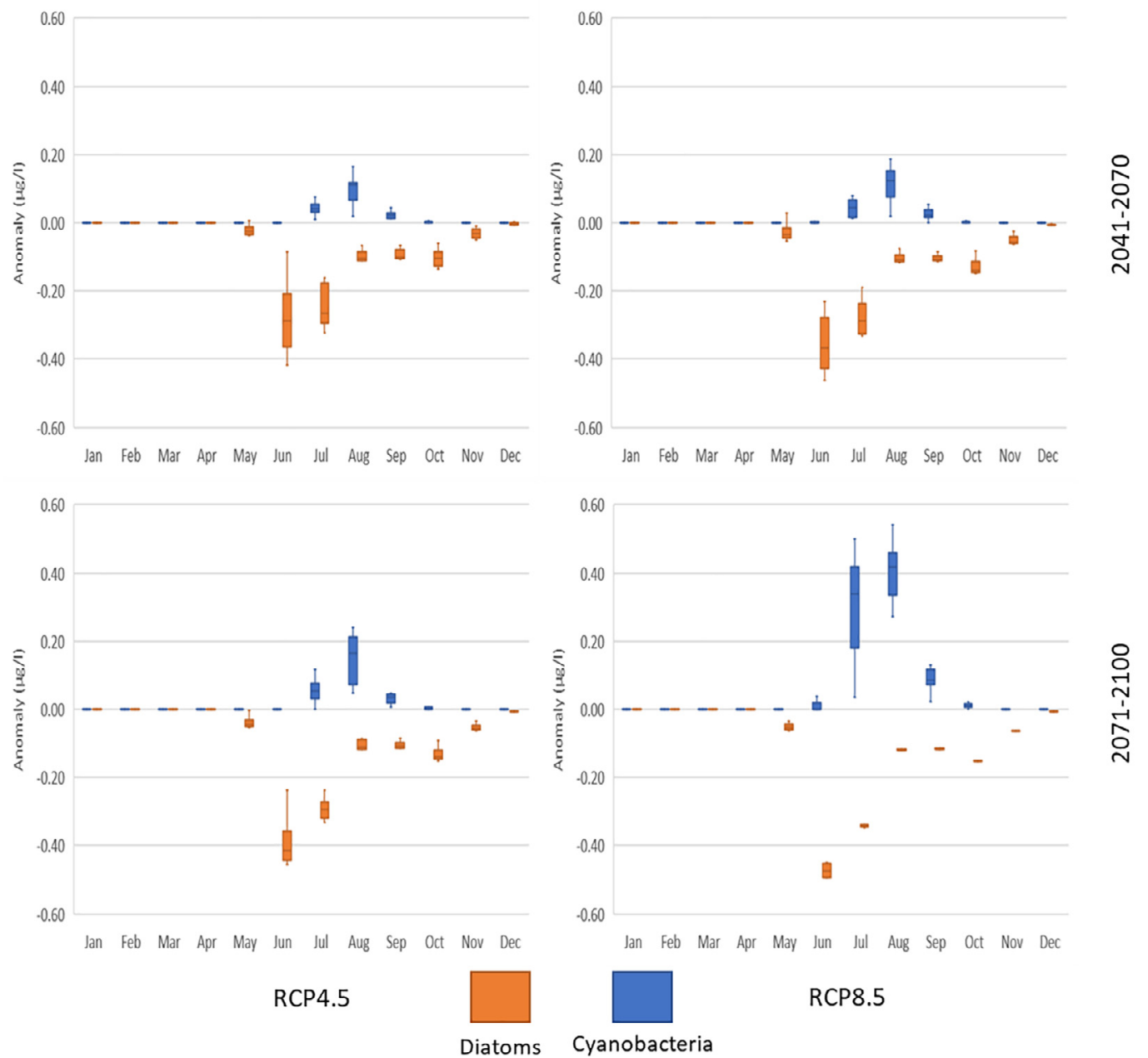

Diatoms Cyanobacteria

Fig. 23. Anomaly $(\mu \mathrm{g} / \mathrm{l})$ in mean monthly concentrations of diatoms and cyanobacteria for RCP4.5 and RCP8.5 in the mid- and late-century periods relative to the baseline period.

in the mid-century period of both scenarios and in the late-century period of RCP4.5 scenarios, and by the complete extinction of diatoms in the late-century period of RCP8.5 scenario. The disappearance of competitors for nutrients creates the conditions for cyanobacterial blooms in PDC. All projections show the same seasonality, with summer concentrations of diatoms diminishing and cyanobacteria increasing. However, differences in changes of concentration can be observed. In the mid-century period, highest variability is attributed to changes in diatoms concentrations, while in the late-century is attributed to changes in cyanobacteria concentrations.

\section{Conclusions}

The main objective of this study was to investigate the potential mid- (2041-2070) and late-century (2071-2100) impacts of climate change, represented by an ensemble of 10 GCM-RCM model combinations on the hydrology of a coastal watershed and on the productivity and community structure of phytoplankton of a coastal salt marsh. In addition, the uncertainty related to the implementation of $10 \mathrm{GCM}$ RCM combinations forced by the emission scenarios RCP4.5 and RCP8.5 for the mid- and late-century periods were analyzed.

Based on our analysis of future climate conditions for the ZRB, we found that all projections showed an increase in annual mean temperature for both RCPs, with greatest increase in the months of July, August and September. In terms of precipitation, the general trend of the four scenarios indicate an increase in the late autumn-winter period and a decrease in the late spring-summer months.

Results based on the SWAT modeling of ZRB indicate that the projected changes in climate will likely modify present hydrological conditions and consequently have implications on future patterns of nitrogen and phosphorus loadings into PDC. Specifically, water discharge is projected to increase in the late autumn-winter period and decrease in summer and so will do nutrient loadings. Results based on the AQUATOX modeling of PDC predict changes in the productivity and community structure of phytoplankton caused by warmer temperatures and altered loadings of nutrients. Projections suggest that new warm tolerant species will replace the current species and will likely generate greater blooms. Also, increased temporal span of nitrogen-limiting conditions and a greater availability of inorganic phosphorus will stimulate the growth of nitrogen-fixing cyanobacteria.

The considerable disparity in projected hydrological and ecological outcomes generated by different GCM-RCM combinations emphasizes the importance of using multi-model methodologies of climate change impact assessment. The results obtained from this study indicate that it is not possible to provide a univocal answer and that studies based on only one GCM-RCM combination should be interpreted with caution as results are highly dependent on the assumptions of the selected combination. Accordingly, more than one combination should be applied in order to consider the uncertainty generated by future climate projections. The use of multiple GCM-RCM projections can provide a more 
robust assessment of climate change impacts on the hydrology and ecology of coastal waters, but at the same time highlight the large uncertainty of these studies, which can affect the decision-making processes related to the management and preservation of sensitive aquatic ecosystems such as those in coastal areas.

Future studies will be necessary to perform similar assessments in the remaining relevant ecological areas of the lagoon of Venice to support the outcomes and conclusions of this research. Moreover, uncertainty originating from the adoption of different hydrological and ecological models, together with different bias-correction methods should be investigated to provide a useful guideline for evaluating the uncertainties in studies of climate change impacts on aquatic ecosystems. This study indicates that local coastal ecosystem could be vulnerable to climatic changes and therefore should be considered in the decision-making processes for ecological conservation and adaptation policies.

\section{Acknowledgements}

This work was financially supported by the European Union Seventh Framework Programme (FP7/2007-2013) under grant agreement no. 269233-GLOCOM (Global Partners in Contaminated Land Management) and by the Italian Ministry of Education, University and Research and the Italian Ministry of Environment, Land and Sea under the GEMINA project (n. 232/2011).

\section{References}

Altieri, A.H., Gedan, K.B., 2015. Climate change and dead zones. Glob. Change Biol. 21 (4), 1395-1406. http://doi.wiley.com/10.1111/gcb.12754.

Arnold, J.G., Srinivasan, R., Muttiah, R.S., Williams, J.R., 1998. Large area hydrologic modeling and assessment part I: Model development. J. Am. Water Resour. Assoc. 34 (1), 73-89. http://doi.wiley.com/10.1111/j.1752-1688.1998.tb05961.x.

ARPAV, 2000. Technical Report on Climatology in the Veneto Region. Regional Agency for the Environment (in Italian: La Caratterizzazione Climatica Della Regione Veneto, Quaderni per l'ambiente Veneto).

ARPAV, 2009. Banca Dati Della Copertura Del Suolo Della Regione Veneto. http://idt. regione.veneto.it (January 1, 2016).

ARPAV, 2013. Climatological Monitoring Network. http://www.arpa.veneto.it/ bollettini/storico/Mappa 2014 TEMP.htm (May 5, 2013).

Aryal, A., Shrestha, S., Babel, M.S., 2018. Quantifying the sources of uncertainty in an ensemble of hydrological climate-impact projections. Theor. Appl. Climatol. http:/ link.springer.com/10.1007/s00704-017-2359-3.

Barbier, E.B., et al., 2011. The value of estuarine and coastal ecosystem services. Ecol. Monogr. 81 (2), 169-193. http://doi.wiley.com/10.1890/10-1510.1.

Bucchignani, E., Montesarchio, M., Zollo, A.L., Mercogliano, P., 2016. High-resolution climate simulations with COSMO-CLM over Italy: performance evaluation and climate projections for the 21st century. Int. J. Climatol. 36 (2), 735-756. http://doi. wiley.com/10.1002/joc. 4379 .

Caldwell, P., Chin, H.S., Bader, D.C., Bala, G., 2009. Evaluation of a WRF Dynamical Downscaling Simulation over California. Climatic Change.

Cataudella, S., Crosetti, D., Massa, F., 2015. Organization Mediterranean Coastal Lagoons: Sustainable Management and Interactions among Aquaculture. Capture Fisheries and the Environment.

Cattaneo, L., et al., 2012. Assessment of COSMO-CLM performances over Mediterranean Area. SSRN Electron. J.

Cervi, F., et al., 2018. Climate-change potential effects on the hydrological regime of freshwater springs in the Italian Northern Apennines. Sci. Total Environ. 622-623, 337-348. http://linkinghub.elsevier.com/retrieve/pii/S0048969717332898.

Chang, H., Evans, B.M., Easterling, D.R., 2001. The effects of climate change on stream flow and nutrient loading. J. Am. Water Resour. Assoc. 37 (4), 973-985. http://doi. wiley.com/10.1111/j.1752-1688.2001.tb05526.x.

Christensen, O.B. et al., 2007. The HIRHAM Regional Climate Model Version 5 Technical Report 06-17. Copenhagen, Denmark.

Cloern, J.E., Jassby, A.D., 2008. Complex seasonal patterns of primary producers at the land-sea interface. Ecol. Lett. 11 (12), 1294-1303. http://doi.wiley.com/10.1111/j. 1461-0248.2008.01244.x.

Collins, W.J., et al., 2011. Development and Evaluation of an Earth-System Model HadGEM2. Geosci. Model Dev. Discuss.

Cook, J., et al., 2016. Consensus on consensus: a synthesis of consensus estimates on human-caused global warming. Environ. Res. Lett. 11 (4) http://stacks.iop.org/17489326/11/i = 4/a = 048002?key = crossref.80d294a6c5d3b7882bc7dc12487e9f39 (September 27, 2016).

Dufresne, J.L., et al., 2013. Climate change projections using the IPSL-CM5 earth system model: from CMIP3 to CMIP5. Clim. Dyn.

Facca, C., Sfriso, A., 2009. Phytoplankton in a transitional ecosystem of the northern adriatic sea and its putative role as an indicator for water quality assessment. Mar.
Ecol. 30 (4), 462-479. http://doi.wiley.com/10.1111/j.1439-0485.2009.00347.x.

Ficklin, D.L., Luo, Y., Luedeling, E., Zhang, M., 2009. Climate change sensitivity assessment of a highly agricultural watershed using SWAT. J. Hydrol.

Fowler, H.J., Blenkinsop, S., Tebaldi, C., 2007. Linking climate change modelling to impacts studies: recent advances in downscaling techniques for hydrological modelling. Int. J. Climatol. 27 (12), 1547-1578. http://doi.wiley.com/10.1002/joc.1556.

Giorgetta, M.A., et al., 2013. Climate and carbon cycle changes from 1850 to 2100 in MPIESM simulations for the coupled model intercomparison project phase 5. J. Adv. Model. Earth Syst. 5 (3), 572-597. http://doi.wiley.com/10.1002/jame.20038.

Giorgi, F., Jones, C., Asrar, G.R., 2009. Addressing Climate Information Needs at the Regional Level: The CORDEX Framework. World Meteorological Organization Bulletin.

Giorgi, F., Gutowski, W.J., 2015. SSRN Regional Dynamical Downscaling and the Cordex Initiative.

Glibert, P.M., et al., 2014. Vulnerability of coastal ecosystems to changes in harmful algal bloom distribution in response to climate change: projections based on model analysis. Glob. Change Biol. 20 (12), 3845-3858. http://doi.wiley.com/10.1111/gcb. 12662.

Gosling, S.N., Taylor, R.G., Arnell, N.W., Todd, M.C., 2011. A comparative analysis of projected impacts of climate change on river runoff from global and catchment-scale hydrological models. Hydrol. Earth Syst. Sci.

Guerzoni, S., Tagliapietra, D., 2006. Atlante Della Laguna. Venezia Tra Terra e Mare, 2nd ed. Marsilio Editori, Venezia.

Harding, L.W., et al., 2015. Climate effects on phytoplankton floral composition in Chesapeake Bay. Estuar. Coast. Shelf Sci. 162, 53-68. http://linkinghub.elsevier. com/retrieve/pii/S0272771414004090.

Hawkins, E., Sutton, R., 2009. The potential to narrow uncertainty in regional climate predictions. Bull. Am. Meteorol. Soc.

Hawkins, E., Sutton, R., 2011. The Potential to Narrow Uncertainty in Projections of Regional Precipitation Change. Climate Dynamics.

Hazeleger, W., et al., 2010. EC-Earth a seamless earth-system prediction approach in action. Bull. Am. Meteorol. Soc. 91 (10), 1357-1364. http://journals.ametsoc.org/ doi/10.1175/2010BAMS2877.1.

Hedin, L.O., et al., 1998. Thermodynamic constraints on nitrogen transformations and other biogeochemical processes at soil-stream interfaces. Ecology 79 (2), 684. http:// www.jstor.org/stable/176963? origin = crossref.

Hempel, S., et al., 2013. A trend-preserving bias correction - the ISI-MIP approach. Earth Syst. Dyn. 4 (2), 219-236. http://www.earth-syst-dynam.net/4/219/2013/.

Holt, J., et al., 2016. Potential impacts of climate change on the primary production of regional seas: a comparative analysis of five European Seas. Prog. Oceanogr. 140, 91-115. http://linkinghub.elsevier.com/retrieve/pii/S0079661115002372.

Huertas, I.E., Rouco, M., Lopez-Rodas, V., Costas, E., 2011. Warming will affect phytoplankton differently: evidence through a mechanistic approach. Proceedings of the Royal Society B: Biological Sciences 278 (1724), 3534-3543.

IPCC. 2013. Cambridge University Press Climate Change 2013: The Physical Science Basis. Contribution of Working Group I to the Fifth Assessment Report of the Intergovernmental Panel on Climate Change.

Jacob, D., et al., 2014. EURO-CORDEX: New High-Resolution Climate Change Projections for European Impact Research. Reg. Environ. Change 14 (2), 563-578. http://link. springer.com/10.1007/s10113-013-0499-2.

Jennings, E., et al., 2009. Impacts of climate change on phosphorus loading from a grassland catchment: implications for future management. Water Res. 43 (17), 4316-4326.

Jeppesen, E., et al., 2009. Climate change effects on runoff, catchment phosphorus loading and lake ecological state, and potential adaptations. J. Environ. Qual. 38 (5), 1930. https://www.agronomy.org/publications/jeq/abstracts/38/5/1930.

Joseph, J., Ghosh, S., Pathak, A., Sahai, A.K., 2018. Hydrologic impacts of climate change: comparisons between hydrological parameter uncertainty and climate model uncertainty. J. Hydrol. 566, 1-22. https://linkinghub.elsevier.com/retrieve/pii/ S0022169418306838.

Khoi, D.N., Hang, P.T.T., 2015. Uncertainty assessment of climate change impacts on hydrology: a case study for the Central Highlands of Vietnam. In: Managing Water Resources under Climate Uncertainty. Springer International Publishing, Cham, pp. 31-44 http://link.springer.com/10.1007/978-3-319-10467-6_2.

Lenderink, G., Buishand, A., van Deursen, W., 2007. Estimates of future discharges of the river rhine using two scenario methodologies: direct versus delta approach. Hydrol. Earth Syst. Sci. 11 (3), 1145-1159.

Mechoso, C.R., Arakawa, A., 2015. NUMERICAL MODELS|General Circulation Models. Encyclopedia of Atmospheric Sciences, Elsevier 153-160. http://linkinghub.elsevier. com/retrieve/pii/B9780123822253001572.

Mooij, W.M., et al., 2010. Challenges and opportunities for integrating lake ecosystem modelling approaches. Aquat. Ecol. 44 (3), 633-667. http://link.springer.com/10. 1007/s10452-010-9339-3.

Mora, C., et al., 2013. The projected timing of climate departure from recent variability. Nature 502 (7470), 183-187. http://www.nature.com/articles/nature12540.

Moss, R.H., et al., 2010. The next generation of scenarios for climate change research and assessment. Nature 463 (7282), 747-756. http://www.nature.com/doifinder/10. $1038 /$ nature08823.

Muerth, M.J., et al., 2013. On the need for bias correction in regional climate scenarios to assess climate change impacts on river runoff. Hydrol. Earth Syst. Sci. 17 (3), 1189-1204.

Nash, J.E., Sutcliffe, J.V., 1970. River flow forecasting through conceptual models Part I A discussion of principles. J. Hydrol. 10 (3), 282-290.

Pandey, V.P., Dhaubanjar, S., Bharati, L., Thapa, B.R., 2019. Hydrological response of Chamelia watershed in Mahakali Basin to climate change. Sci. Total Environ. 650, 365-383. https://linkinghub.elsevier.com/retrieve/pii/S0048969718334892. 
Park, R.A., Clough, J.S., Wellman, M.C., 2008. AQUATOX: modeling environmental fate and ecological effects in aquatic ecosystems. Ecol. Model. 213 (1), 1-15.

Pesce, M., et al., 2018. Modelling climate change impacts on nutrients and primary production in Coastal Waters. Sci. Total Environ. 628-629, 919-937. http:// linkinghub.elsevier.com/retrieve/pii/S0048969718305217.

Rabalais, N.N., Eugene Turner, R., Díaz, R.J., Justić, D., 2009. Global change and eutrophication of coastal waters. ICES J. Mar. Sci. 66 (7), 1528-1537.

Radchenko, I., et al., 2017. Climate change impacts on runoff in the Ferghana Valley (Central Asia). Water Resour. 44 (5), 707-730. http://link.springer.com/10.1134/ S0097807817050098.

Raimonet, M., Cloern, J.E., 2016. Estuary-ocean connectivity: fast physics, slow biology. Glob. Change Biol http://www.ncbi.nlm.nih.gov/pubmed/27801968 (November 18, 2016).

Rockel, B., Will, A., Hense, A., 2008. The regional climate model COSMO-CLM (CCLM). Meteorol. Z. 17 (4), 347-348. http://www.schweizerbart.de/papers/metz/detail/17/ 56726/The Regional Climate Model COSMO CLM CCLM?af = crossref.

Rummukainen, M., 2010. State-of-the-art with regional climate models. Wiley Interdiscip. Rev. Clim. Change 1 (1), 82-96.

SAMANET, 2013. Real-Time Monitoring Network SAMANET. Unpublished Raw Data.

Sarretta, A., et al., 2010. Sediment budget in the Lagoon of Venice, Italy. Cont. Shelf Res. 30 (8), 934-949. http://linkinghub.elsevier.com/retrieve/pii/S027843430900209X.

Schmidtko, S., Stramma, L., Visbeck, M., 2017. Decline in global oceanic oxygen content during the past five decades. Nature 542 (7641), 335-339. http://www.nature.com/ doifinder/10.1038/nature21399.

Scoccimarro, E., et al., 2011. Effects of tropical cyclones on ocean heat transport in a high-resolution coupled general circulation model. J. Clim. 24 (16), 4368-4384.

Shen, M., et al., 2018. Estimating uncertainty and its temporal variation related to global climate models in quantifying climate change impacts on hydrology. J. Hydrol. 556, 10-24. https://linkinghub.elsevier.com/retrieve/pii/S0022169417307588.

Snickars, M., Weigel, B., Bonsdorff, E., 2015. Impact of eutrophication and climate change on fish and zoobenthos in coastal waters of the Baltic Sea. Mar. Biol. 162 (1), 141-151. http://doi.wiley.com/10.1111/gcb.12754.

Somura, H., et al., 2009. Impact of climate change on the Hii river basin and salinity in Lake Shinji: a case study using the SWAT model and a regression curve. Hydrol. Process.
Strandberg, G., et al., 2014. CORDEX Scenarios for Europe from the Rossby Centre Regional Climate Model RCA4. Reports Meteorology and Climatology, pp. 116.

Teklesadik, A.D., et al., 2017. Inter-model comparison of hydrological impacts of climate change on the Upper Blue Nile Basin using ensemble of hydrological models and global climate models. Clim. Change 141 (3), 517-532. http://link.springer.com/10. 1007/s10584-017-1913-4.

Teutschbein, C., Seibert, J., 2012. Bias correction of regional climate model simulations for hydrological climate-change impact studies: review and evaluation of different methods. J. Hydrol. 456-457, 12-29.

Tomozeiu, R., Agrillo, G., Cacciamani, C., Pavan, V., 2014. Statistically downscaled climate change projections of surface temperature over Northern Italy for the periods 2021-2050 and 2070-2099. Nat. Hazards 72 (1), 143-168. http://link.springer.com/ $10.1007 /$ s11069-013-0552-y.

VanMeijgaard, E., et al., 2008. The KNMI Regional Atmospheric Climate Model RACMO Version 2.1 - Technical Report 302. De Bilt, The Netherlands.

van Vliet, J., den Elzen, M.G.J., van Vuuren, D.P., 2009. Meeting radiative forcing targets under delayed participation. Energy Econ.

Voldoire, A., et al., 2013. The CNRM-CM5.1 global climate model: description and basic evaluation. Clim. Dyn. 40 (9-10), 2091-2121. http://link.springer.com/10.1007/ s00382-011-1259-y.

Winder, M., Sommer, U., 2012. Phytoplankton response to a changing climate. In: Phytoplankton Responses to Human Impacts at Different Scales. Springer Netherlands, Dordrecht, pp. 5-16 http://www.springerlink.com/index/10.1007/ 978-94-007-5790-5_2.

Xue, Y., et al., 2014. A review on regional dynamical downscaling in intraseasonal to seasonal simulation/prediction and major factors that affect downscaling ability. Atmospheric Research.

Zirino, A., et al., 2016. Nitrogen to phosphorus ratio in the Venice (Italy) lagoon (2001-2010) and its relation to macroalgae. Mar. Chem. 180, 33-41. http:// linkinghub.elsevier.com/retrieve/pii/S0304420316300020.

Zollo, A.L., et al., 2016. Extreme temperature and precipitation events over Italy: Assessment of high-resolution simulations with COSMO-CLM and future scenarios. International Journal of Climatology 36 (2), 987-1004. http://doi.wiley.com/10. 1002/joc. 4401. 